\title{
WORKER-FIRM MATCHING AND UNEMPLOYMENT IN TRANSITION TO A MARKET ECONOMY: (WHY) ARE THE CZECHS MORE SUCCESSFUL THAN OTHERS?'
}

\author{
Daniel Münich * \\ Jan Svejnar ${ }^{* *}$ \\ Katherine Terrell ${ }^{* * *}$
}

First Draft, October 1997

Revised, December 1998

JEL Number: P2, J4, J6, C33

${ }^{1}$ In preparing the paper, the authors were in part supported by National Science Foundation Grant No. SBR-9512001. Münich and Svejnar's research was also in part supported by PHARE-ACE grant No. P96-6095-R and an institutional grant from the Grant Agency of the Czech Republic (GACR No. 402/95/0789) to the Economics Institute of the Academy of Sciences of the Czech Republic. Münich and Terrell's research was in part supported by the National Council for Soviet and East European Research (Contract No. 812-32). Finally, Münich's research was in part supported by the Research Support Scheme (RSS/HESP No. 865/1995). The authors would like to thank Elie Applebaum, Olivier Blanchard, Robert Dunn, Randall Filer, Jan Kmenta, Lubomír Lízal, Dale Mortensen and participants of the October 1997 William Davidson Institute Conference on Labor Markets in Transition Economies for valuable comments. The usual disclaimer applies.

\footnotetext{
* CERGE-EI, Prague.

** The William Davidson Institute at the University of Michigan Business School, Department of Economics, University of Michigan, and CERGE-EI, Prague.

*** The William Davidson Institute at the University of Michigan Business School.
} 


\section{Introduction}

A fundamental systemic feature of the Soviet-type economies was the nonexistence of open unemployment. ${ }^{2}$ An equally distinguishing feature of the transition to a market economy has been the emergence of double digit unemployment rates in all the rapidly transforming economies except for the Czech Republic. In the Czech Republic, the unemployment rate remained at mere 3-4 percent throughout the first half of the 1990s and only rose to 6-7 percent during the recession of 1998 . The gravity of the unemployment problem and the discrepancy between the unemployment experience of the Czech Republic and the other Central and East European (CEE) economies, depicted in Figure 1, poses a fundamental academic as well as policy-related puzzle. Why has the Czech Republic been exhibiting so much lower unemployment rate than its traditional counterpart republic, Slovakia, and the other CEE economies? Until 1993, Slovakia and the Czech Republic have after all shared the same currency, legal system and institutional framework. Moreover, except for unemployment, aggregate economic indicators of the two countries were similar in the early 1990s (Dyba and Svejnar, 1994, 1995, Ham et al., 1998). Why then have the Slovak labor market indicators been similar to those of Bulgaria, Hungary, Poland, and other transition economies, rather than those of the Czech Republic? What are the policy implications?

An important part of the answer to the above questions is that from the time unemployment started appearing in CEE in the early 1990s, the Czech Republic has had a dramatically higher outflow rate of individuals from the unemployment state to employment than did the other CEE economies (see e.g., Boeri, 1994, Boeri and Scarpetta, 1995 and Ham, Svejnar and Terrell (HST),

\footnotetext{
${ }^{2}$ Open unemployment did exist in the Yugoslav labor-managed economy. As planning gradually gave way to market forces, one could observe unemployment also in Hungary. 
1999). Using OECD data, HST (1998), for instance report 1991 outflow rates to be 17.1 in the Czech Republic but only 4.8 in Slovakia. Similarly, their data for 1992 indicate the outflow rate to be 26.6 in the Czech Republic, 10.2 in Slovakia, 6.6 in Poland, and 4.3 in Hungary. Moreover, other possible causes of the less rapid rise of unemployment in the Czech Republic in the early 1990s, such as lower inflow rates into unemployment due to higher government subsidies to Czech firms or to more marked declines in Czech labor force participation, are not borne out by the data. ${ }^{3}$ These basic findings suggest that one needs a thorough understanding of the determinants of outflow from unemployment and the matching of the unemployed and vacancies in the Czech Republic and the other CEE countries. While HST $(1998,1999)$ examine the outflow issue, in the present paper we analyze the process of matching of the unemployed and vacancies.

The literature on matching functions usually assumes that the outflow (number of individuals flowing) from unemployment to employment $O$ is a function of the number of unemployed $U$ and the number of posted vacancies $V, O=f(U, V)$. Matching is seen as a search process, with both the unemployed and employers with vacant positions striving to find the best match, given exogenous factors such as skill and spatial mismatch, as well as availability of information. Some authors (e.g.,

\footnotetext{
${ }^{3}$ In the first few years of the transition, as the unemployment rate rose from zero to double digits in most CEE economies, the Czech Republic had a similar rate of inflow of the employed into unemployment as the other economies. Burda (1994) for instance reports 1992 monthly inflow into unemployment rates to be .5 in the Czech Republic, .8 in the Slovak Republic, .5 in Hungary, and .6 in Poland. Ham et al. (1998) use OECD data and report the 1992 inflow rates to be 0.9 for the Czech Republic, Hungary and Poland, and 1.3 for Slovakia. (After the double digit unemployment rates were established in all the CEEs except for the Czech Republic, the inflow rates started to be lower in the Czech Republic than these other economies.) Moreover, as Schaffer (1995) shows, budgetary subsidies to firms were virtually eliminated in the Czech Republic as well as other CEE economies in the early 1990s, thus providing similar pressure in all these economies to release excess labor. Finally, as Paukert (1995) demonstrates, labor force participation declined in all the CEE economies and not just the Czech Republic.
} 
Blanchard and Diamond, 1989, Pissarides, 1990, and Storer, 1994) expect the matching function $f$ to display constant returns to scale, while others have identified reasons, such as externalities in the search process, heterogeneity in the unemployed and vacancies and lags between matching and hiring, why increasing returns may prevail (e.g., Diamond, 1982, Coles and Smith, 1994, Profit, 1996, and Mortensen 1997). Increasing returns are conceptually important because in many models they constitute a necessary condition for multiple equilibria and provide a rationale for government intervention. In this paper we show that increasing returns may have been an important phenomenon in the Czech Republic as compared to Slovakia and by implication the other CEE economies.

In specifying the matching process, the most frequently used functional form is Cobb-Douglas

$$
\ln O_{i, t}{ }^{\prime} \quad c \% \beta_{u} \ln U_{i, t \& 1} \% \beta_{v} \ln V_{i, t \& 1}
$$

where, $U_{i, t-1}$, and $V_{i, t-1}$ are the number of unemployed and vacancies in area $\mathrm{i}$ at the end of period $t-1$, respectively, $O_{i, t}$ denotes the outflow to jobs (the number of successful matches between the currently unemployed and current vacancies) and constant $c$ captures the efficiency of matching.

In view of the serious unemployment problem in the transition economies, the literature on the matching of unemployed and vacancies in these economies has grown rapidly. It has also produced contradictory results, in part because the studies use different methodologies and data. Methodologically, the studies differ especially with respect to the specification of the matching function and treatment of returns to scale, the inclusion in equation (1) of other variables that might affect outflows and the extent to which they use static or dynamic models. In terms of data, the studies differ in whether they use annual, quarterly or monthly panels of district-level or more aggregate (regional) data and whether they cover short or long time periods. None of the studies 
adjusts the data for the varying size of the unit of observation (district or region) which, as we show presently, may generate biased estimates of the returns to scale in many studies. ${ }^{4}$

The contradictory findings of the existing studies, as well as the Czech Republic's high outflow from unemployment relative to Slovakia and the other CEE economies, have led us to carry out comparative analysis of matching in the Czech and Slovak republics. As we mentioned earlier, our focus on the Czech and Slovak Republics is motivated by the fact that they represent a unique laboratory, in which we can hold constant many initial conditions. Comparing them is hence methodologically preferable than comparing the Czech Republic to other CEE countries with differing conditions. From the methodological standpoint, a particularly important advantage of using the Czech and Slovak data is that all employers have been legally obliged to report all vacancies to the government labor offices. This makes the measured vacancy variable in these two republics much more accurate than the vacancy measures used in most other economies, East or West. ${ }^{5}$

Unlike other studies, we also use a more flexible and up-to-date empirical methodology and superior data. In particular, unlike other studies we a) use a translog rather than the more restrictive Cobb-Douglas specification of the matching function, b) test and carefully control for the endogeneity of explanatory variables, c) account for the presence of a spurious scale effect introduced by the

\footnotetext{
${ }^{4}$ The principal studies in this area are Burda (1993), who uses monthly Czech and Slovak district-level data from 1990 to1992, Boeri (1994), who uses 1991-93 regional panel data for the Czech Republic, Hungary Poland, and Slovakia, Svejnar, Terrell and Münich (1994, 1995), who use annual 1992 and 1993 data from the Czech and Slovak Republics, Lubyova and van Ours (1994), who use 1990-93 monthly data for Slovakia and 1991-93 data for the Czech Republic, Boeri and Scarpetta (1995), who use monthly data for districts/regions in Poland (1992-93), Hungary (1991-94), the Czech Republic (1991-94), and Slovakia (1990-93), Burda and Lubyova (1995) who use monthly and quarterly Czech and Slovak data from 1992 to 1994, Boeri and Burda (1995), who use Czech district-level data over the period 1992-1994, Burda and Profit (1996), who use district and regional 1992-94 data from the Czech Republic, and Profit (1996), who uses Czech district data during 1992-94. For a brief survey of the principal studies se Munich et al. (1997).

${ }^{5}$ As we discuss presently, one of the goals of this study is to examine the effect of active labor market (training) policies on matching. In this context it is important to note that the vacancy data do not include slots in these active labor market policy programs.
} 
varying size of units of observation (districts), and d) use five (1991-96) years of comparable monthly data from all districts in the Czech and Slovak Republics . Unlike most studies, we also separate the effects of new and longer term unemployed, estimate the effects of several factors on outflow from unemployment, employ a dynamic specification and estimate on contiguous panels to allow for dynamic adjustment and regime changes during the period of economic transition, and control for the heterogeneity of unemployed searchers. ${ }^{6}$ Like other studies, we do not address the issue of the matching of vacancies with employed individuals.

We start in Section 2 by presenting our estimating framework and explaining how it overcomes some of the principal problems of the existing studies. In Section 3 we describe our data and the implementation of our econometric model. In Section 4 we present basic statistics and our econometric estimates. We conclude in Section 5.

\section{The Estimating Framework}

Theories of search and matching generally do not imply a particular functional form of the matching function and most studies use the Cobb-Douglas form. ${ }^{7}$ We minimize the potential bias stemming from this restrictive specification by using a translog form. We also include separately the new (current period) entrants into unemployment and those already unemployed in order to allow for the finding by Coles and Smith (1994) that new entrants interact with posted vacancies in a different manner than those already unemployed. ${ }^{8}$

\footnotetext{
${ }^{6}$ Few studies have accounted for one or at most two of these latter problems.

7 There are of course exceptions. Pissarides (1990) for instance shows that in his theoretical model the CobbDouglas function could represent a useful approximation. In the empirical work, Boeri (1994) estimates a CobbDouglas matching function of unemployment and vacancies, with unemployment entering as a CES function of short and long term unemployed. Warren (1996) also uses more complex specifications in the U.S. context.

${ }^{8}$ Ideally, one would also like to separate the newly posted vacancies from the existing ones. While our data on vacancies are of better quality than those from most other countries, they do not allow us to identify the vintage of vacancies.
} 
We start with the following dynamic specification

$\ln O_{i, t}=a_{0}+?_{0} \ln O_{i, t-1}+\underset{k=u, s, v}{3} \beta_{k} \ln ?_{k, i, t}+.53 \underset{k=u, s, v \quad}{3} ?_{k=u, s, v} \ln ?_{l, i, t} \ln ?_{l, i, t}+\mathrm{dNW}_{i}+\mathrm{g}_{i, t}$

where the second variable on the right hand side is the lagged value of the dependent variable (the number of individuals flowing out from unemployment) and $X_{u, i, t} / U_{i, t} X_{s, i, t} / S_{i, t} X_{v, i, t} / V_{i, t}$ represent those already unemployed, those flowing into unemployment in the current period and the number of lagged vacancies, respectively. $\boldsymbol{W}_{i}$ is a $K_{l} \times 1$ vector of time invariant, district-specific variables and $\boldsymbol{d}$ is a $K_{1} \times 1$ vector of associated parameters. The term $\mathrm{g}_{, t}$ represents the unexplained stochastic part of the matching process. We start with a general specification of the error as $\mathrm{g}_{\mathrm{i}, t} / ?_{i}+v_{i, t}$, where ${ }_{i}$ stands for matching efficiency that varies across districts but remains constant over time and $v_{i, t}$ is the effect of unobservable factors that vary across districts and over time. In order to make the model identifiable, we make the usual assumptions that $E ?{ }_{i}=E v_{i, t}=0, E ?{ }_{i} v_{i t}=0, E ?{ }_{i} \boldsymbol{W}_{i}=\boldsymbol{0}, E ?{ }_{i}{ }_{j}=s_{?}{ }^{2}$ if $i=j$ and zero otherwise, and $E v_{i t} \nu_{j s}=s_{u}{ }^{2}$ if $i=j \& t=s$ and zero otherwise.

The term $? \ln O_{t-1}$ with $?<1$ allows for partial adjustment in the matching process which may be brought about by the fact that (a) the acceptance of a job offer precedes the reported date of a match (start of work), with no search taking place during the interim period, and (b) information about new vacancies is not diffused instantly to all job searchers. Unlike other studies, we also analyze the nature and magnitude of differences in matching efficiency across districts. We use the two-stage Anderson-Hsiao Instrumental Variable (AHIV) procedure (Hsiao, 1986) to estimate the effects of district-specific factors that may influence the efficiency of matching.

\subsection{The Estimation Strategy}

In the first stage of the AHIV procedure, we estimate $\beta$ 's and ?'s of the matching function by exploiting the monthly within-district variation in these time varying variables. We use these 
consistent parameter estimates of the basic matching function (without variables $\boldsymbol{W}_{i}$ ) and the mean $\log$ values of the associated variables to calculate district-specific efficiency residuals that represent the unexplained part of the basic matching process. In the second stage, we regress these efficiency residuals on explanatory variables $\boldsymbol{W}_{i}$ that are time invariant or have annual frequency and we obtain estimates of parameters $d .{ }^{9}$ While we are aware of the limitations of the two-stage procedure, we use it because there is no straightforward single-stage method that deals adequately with the varying frequency of observations, partial adjustment and endogeneity of regressors, as discussed below.

\section{The First Stage Estimation}

The dependent variable and the error term in equation (2) are likely to contain a districtspecific effect. The data transformations that are most widely used to remove this effect are mean deviations and first differences. The mean deviation transformation is appropriate if the explanatory variables are strongly exogenous with respect to their lagged values. However, variables $O_{t-1}, U_{t-1}$ and $V_{t-1}$ are predetermined by the previous matching process and hence are not strictly exogenous. In particular, the lagged outflow is predetermined by definition, while unemployment and vacancies are partially predetermined by all preceding outflows. To see these links, note that the number of unemployed and vacancies at time $t-1$ is given by identities

$$
\begin{aligned}
& U_{i, t \& 1} / U_{i, t \& 2} \% S_{i, t \& 1} \& O_{i, t \& 1} \\
& V_{i, t \& 1} / V_{i, t \& 2} \% Z_{i, t \& 1} \& O_{i, t \& 1}
\end{aligned}
$$

\footnotetext{
${ }^{9}$ As we mention below, we assume that $\boldsymbol{W}_{i}$ is uncorrelated with the instrumental variables used to predict the other explanatory variables in equation (2).
} 
where $Z_{i, t-1}$ stands for the net inflow of new vacancies. Since both $U_{i, t-1}$ and $V_{i, t-1}$ depend on $O_{i, t-1}$, which in turn depends on $v_{i, t-1}, U_{i, t-1}$ and $V_{i, t-1}$ are only weakly exogenous. ${ }^{10}$ In this case, the mean deviation transformation leads to biased parameter estimates because of the correlation of the transformed values of weakly exogenous variables with the transformed error term $\mathrm{g}_{, t}$ (Appendix I).

The first difference transformation is often viewed as being superior to mean deviations in overcoming the problem of weak exogeneity and measurement errors. Although first differencing does not fully eliminate the problem of endogeneity, it permits one to identify the parameters using the AHIV or Generalized Method of Moments methods. In particular, transforming $U_{t-1}$ and $V_{t-1}$ into first differences yields:

$$
\begin{aligned}
& ? U_{i, t \& 1}{ }^{\prime} U_{i, t \& 1} \& U_{i, t \& 2}{ }^{\prime} S_{i, t \& 1} \& O_{i, t \& 1} \\
& ? V_{i, t \& 1}{ }^{\prime} V_{i, t \& 1} \& V_{i, t \& 2}{ }^{\prime} Z_{i, t \& 1} \& O_{i, t \& 1}
\end{aligned}
$$

Both first differences are still affected by $O_{i, t-1}$ and hence correlated with ? $v_{i, t}=v_{i, t}-v_{i, t-1}$. However, further lags of ? $U$ and ? $V$ are uncorrelated with $v_{i, t-1}$ and therefore can be used as valid instruments to identify parameters of interest. The issue is whether the instruments have adequate explanatory power. Moreover, first differencing decreases significantly the variance of the explanatory variables while doubling the variance of the error term and potential measurement error. This in turn leads to higher standard errors of estimated parameters. In view of these tradeoffs, we transform equation (2) into deviations from forward means and compute instruments as deviations from backward means. This transformation maintains a relatively large variance in the variables as well as a small variance

\footnotetext{
${ }^{10}$ These identities assume that all matches are brought about by the reported unemployed and vacancies (there being no out-of-register matching). Other forms of matching may create more complicated identities but will not eliminate the problem of weak exogeneity.
} 
in the error term and it avoids the problem of weak exogeneity. ${ }^{11}$ In our empirical work we find that the explanatory power of these instruments is adequate. ${ }^{12}$

\section{Adjusting for Varying Size of Districts}

Since the literature on matching has not taken into account the variation in the size of the unit of observation (in our case the district ${ }^{13}$ ) many of the existing studies may have generated biased estimates. The reason for the bias, explained in detail in Appendix IV, relates to the fact that the size of a district, measured for instance by its labor force $L_{i}$, tends to be positively correlated with the values of $O_{i}, U_{i}, S_{i}$ and $V_{i}$. In this situation, when district-level variables are not adjusted for the size of the district labor force, the intercorrelations among $O_{i}, U_{i}, S_{i}$ and $V_{i}$ tend to be biased upward on account of the variation in the size of districts (see Appendix Table A2 for an illustration). The usual Cobb-Douglas specification based on cross-section data then provides biased estimates of coefficients unless there are constant returns to scale or the unadjusted $U_{i}$ and $V_{i}$ are uncorrelated with the labor force $L_{i}$. The direction of the bias of $\beta_{u}\left(\beta_{v}\right)$ is negative if $U_{i}\left(V_{i}\right)$ is positively correlated with $L_{i}$ and matching displays increasing returns to scale. Either decreasing returns to scale or negative correlation (but not both) in turn lead to a positive bias. Therefore, if the matching process does not exhibit constant returns, the bias is likely to cause an incorrect acceptance of the constant returns hypothesis. The bias, and therefore the likelihood of an incorrect acceptance of the constant returns

\footnotetext{
${ }^{11}$ A detailed description of the transformation is provided in Appendix II. Note that relative to a first difference specification, our form of mean deviations generates (i) a higher variance in variables (since the distance of individual observations from the mean tends to be greater than the distance between two successive observations) and (ii) a smaller variance of the error term (since the variance of the mean deviation error is approximately equal to the variance of the original error term, while the variance of the difference in successive error terms is twice the variance of the original error term).

${ }^{12}$ The instruments explain $20 \%$ to $75 \%$ of variation in explanatory variables. The lowest explanatory power of instruments was for vacancies (20-30\%), and the highest power was for outflows (60-70\%).

${ }^{13}$ There are several possible measures of district size. We use the district labour force, but the results would not be materially affected by using other measures.
} 
hypothesis, is greater, the greater is the portion of the correlation of $U_{i}$ and $V_{i}$ with $L_{i}$ that is due to differences in the size of the district labor force. As we show in Appendix IV, the bias is very similar to that stemming from an omitted variable problem. In what follows we call this phenomenon the spurious scale effect. ${ }^{14}$

It can be shown that the spurious scale effect is avoided if one uses panel data and estimates a Cobb-Douglas function by fixed effects. In this case, the fixed effects transformation removes the spurious scale effects together with the district-specific time invariant effects. Unfortunately, the spurious scale effect problem remains even under fixed effects if the real matching function is more complex than Cobb-Douglas. As we show in Appendix IV, in the case of our translog specification with three factors, the adjusted model should be estimated as

$$
\begin{aligned}
& ? \ln O_{i, t}{ }^{\prime} \quad\left[\beta_{u} \& L_{i}\left({ }{ }_{u u} \% ?{ }_{u s} \% ?{ }_{u v}\right)\right] ? \ln X_{u, i, t} \% \\
& \%\left[\beta_{s} \& L_{i}\left(?_{s s} \% ? u s \% ? ?_{s v}\right)\right] ? \ln X_{s, i, t} \% \\
& \%\left[\beta_{v} \& L_{i}\left(?_{v v} \% ? u v \% ?_{s v}\right)\right] ? \ln X_{v, i, t} \% \\
& \% .5{ }_{k^{\prime}}^{\mathrm{j}}{ }_{u, s, v} l^{\prime}{ }_{u, s, v}^{\mathrm{j}} ? ? ?_{k l} \ln X_{k, i, t} \ln X_{l, i, t}
\end{aligned}
$$

The estimated coefficients of direct effects $\beta$ 's are hence identical with the coefficients of the unadjusted model only if the sums of ? coefficients in the parentheses are equal to zero. As we show presently, this is

also related to the necessary but not sufficient conditions for constant returns. In general, with bars denoting means of variables, the formula for short-term elasticities computed at the means of

\footnotetext{
${ }^{14}$ An interesting question for future research is whether the size of districts and regions, the usual units of observation in the matching function studies, tends to be determined by an arbitrary administrative fiat or an endogenous optimization process of population settlements, based on historical economic forces that are in principle similar to an optimization process determining the size of firms.
} 
explanatory variables is:

$$
\frac{\ln \frac{O}{L}}{\ln \frac{X_{k}}{L}}{ }^{\prime} \hat{\beta}_{k} \%{ }_{l^{\prime}} \mathrm{j}_{u, s, v} ?_{k l} \overline{\frac{X_{l}}{\ln }}{ }^{\prime} \hat{\beta}_{k} \%_{l^{\prime}}{ }_{u, s, v} ?_{k l} \overline{\ln X_{l}} \& \overline{\ln L}
$$

It is obvious that the last term on the right hand side disappears if the sums of ? are zero. In this case expression (8) becomes identical to the formula for elasticities in the unadjusted model as presented in Appendix III. ${ }^{15}$

\section{The Second Stage Estimation}

In the second stage we estimate $d s^{\prime}$ which reflect the impact of district-specific variables $\boldsymbol{W}_{i}$ on the efficiency of matching, given unemployment, inflow into unemployment and vacancies. Using the consistent estimates from the first stage, we compute the (average annual) unexplained first stage residuals

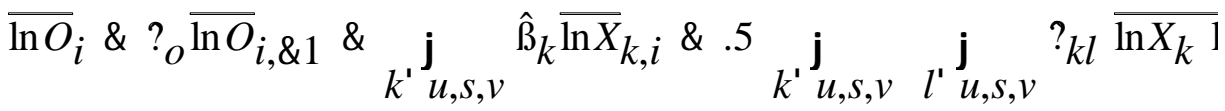

$$
\begin{aligned}
& \left.\mathrm{a}_{0} \% \mathrm{~d}\right)_{\boldsymbol{i}} \% ?_{i}
\end{aligned}
$$

and use them on the left hand side of the following annual cross section OLS regressions:

where the variables $O$ and $X$ are adjusted for district size.

\section{Selecting the Functional Form}

Since there are no strong a priori reasons to expect the matching function to have a given form, we start with the translog function, which nests a number of simpler functional forms, including the CobbDouglas. We allow the new entrants into unemployment to be a separate factor from those already

\footnotetext{
${ }^{15}$ Note that our discussion of the spurious scale effect identifies problems that arise under various returns to scale but does not per se assume any particular returns to scale.
} 
unemployed and test the following four hypotheses about the appropriate form of the matching function and the separability of the already unemployed and the new entrants: ${ }^{16}$

1. Weak separability of $X_{u}$ and $X_{s}$ from $X_{v}$ : This hypothesis presumes that the matching function has the form

$$
\ln O^{\prime} f\left[g\left(\ln X_{u}, \ln X_{S}\right), \ln X_{v}\right]
$$

where $g\left(X_{u}, X_{s}\right)$ is a translog combination of factors $X_{u}$ and $X_{s}$ and $f$ is a translog function of input aggregates. A test of this hypotheses represents testing whether $\beta_{u} / \beta_{s}-?_{u v} / ?_{s v}=0$.

2. Strong separability of $X_{u}$ and $X_{s}$ from $X_{v}$ : This hypothesis presumes that the matching function has the form

$$
\ln O^{\prime} f\left[g\left(\ln X_{u}, \ln X_{S}\right), \ln X_{v}\right]
$$

where $g\left(X_{w} X_{s}\right)$ is a translog combination of factors $X_{u}$ and $X_{s}$ and $f$ is a Cobb-Douglas function of input aggregates. A test of this hypothesis amounts to testing whether $?_{u v}=? ?_{s v}=0$.

3. Cobb-Douglas function: This hypothesis presumes that Cobb-Douglas appropriately represents the matching process. A test of this hypothesis requires testing whether $?_{u u}=?_{s s}=?_{v v}=?_{u s}=?_{u v}=?_{s v}=0$. 4. Constant Returns to Scale: This hypothesis presumes that the matching process displays constant returns to scale. A test of this hypothesis consists of testing the following four linear restrictions:

$$
\begin{aligned}
& ?_{u u}+?_{u s}+?_{u v}=0 \\
& ?_{v v}+?_{u v}+?_{s v}=0 \\
& ?_{s s}+?_{u s}+?_{s v}=0 \\
& \beta_{u}+\beta_{s}+\beta_{v}=1
\end{aligned}
$$

\footnotetext{
${ }^{16}$ See Denny and Fuss (1977).
} 
The first three hypotheses relate to the degree of substitutability among the three factors. The fourth hypothesis addresses the returns to scale observed in the matching process.

\section{The Data and Variable Definition}

In order to produce the best possible parameter estimates, we have assembled an extensive panel of data on all 76 Czech and 38 Slovak districts. The data cover the period January 1991 - December 1996 and contain monthly observations for the following variables in the first stage of estimation:

$O_{i, t}=$ the number of individuals flowing from unemployment in district $i$ at time $t$; In the Czech Republic we have data on total outflow and outflow to jobs; In Slovakia we have total outflow only; ${ }^{17}$ $U_{i, t-1}=$ the number of unemployed in district $i$ at time $t-1$;

$S_{i, t}=$ the normalized number of individuals flowing into unemployment in district $i$ at $t ;^{18}$ $V_{i, t-1}=$ the number of vacancies in district $i$ at time $t-1$;

Since a) outflow to jobs is a theoretically preferred variable to total outflows and b) only total outflow is available for Slovakia, we carry out the estimation for the Czech Republic using both measures and compare them to the Slovak findings based on total outflow. As we show below, the Czech estimates based on total outflow and outflow to jobs are similar. ${ }^{19}$ As a result, the lack of data on outflow to jobs in Slovakia does not appear to affect dramatically the validity of our Czech-Slovak comparison.

\footnotetext{
${ }^{17}$ The Slovak data contain information on outflow to jobs intermediated by the district labor offices (see e.g., Burda and Lubyova, 1995). However, an examination of these data indicates that this outflow is relatively low compared to the total expected outflow to jobs.

${ }^{18}$ Although the individuals flow into unemployment in the same calendar month, they enter on different days within the month. This means that they face different probabilities of finding vacancies during the calendar month. Assuming, that the inflow is approximately uniform over the month, we multiply the total monthly inflow by .5.

${ }^{19}$ Total outflows and outflows to jobs are positively correlated, with the latter representing about 75 percent of the former in the Czech Republic.
} 
In the second stage of estimation, we use as regressors structural and policy variables that are time invariant or are measured with annual frequency. While there are numerous conjectures and empirical evidence about the effects on matching of variables such as unemployment duration, educational structure of the unemployed and extent of government policies, no formal theory exists in this area. We have therefore collected data on what we consider to be important district-level variables and carry out an exploratory analysis based on these variables. The tentative nature of this set of variables provides another reason for carrying out the estimation in two stages. With $t$ denoting annual frequency, the district-level variables that we use in the second stage are:

$P U E D 2_{i, t}=$ the proportion of unemployed with secondary education;

$P U E D 3_{i, t}=\quad$ the proportion of unemployed with university education;

$P L T U_{i, t}=\quad$ the proportion of unemployed with spells longer than nine months;

$Q_{i, t}=\quad$ industrial output in million crowns per member of the district labor force,

$E_{i, t}=\quad$ the number of firms with fewer than 25 employees per member of the labor force;

$I A 90_{i}=\quad$ the ratio of the value of agricultural production to industrial production in 1990;

$L D I S_{i}=\quad$ the natural logarithm of the average distance (in kilometers) from the district capital to the Austrian or West German border (Austrian border for Slovakia);

$D E N S_{i}=\quad$ the density of population in the district (individuals per $\mathrm{km}^{2}$ );

$A L M P_{i, t}=\quad$ the logarithm of expenditures on active labor market programs per member of the labor force;

$S U D_{i}=\quad$ a dummy variable coded 1 if the district falls into the Sudeten lands of the Czech Republic. Education is included to test the hypothesis that more educated individuals are better able to find jobs. Demand for individuals with human capital is hypothesized to have increased during the transition 
and they are also expected to be more adept at searching for jobs. The share of unemployed with spells longer than nine months is included because the long-term of unemployed may have different unobservable characteristics than the short term unemployed. They may suffer from discouragement, stigma, loss of skills, and skill mismatch.

The ratio of industrial output to the labor force controls for the differences in the level of economic activity in the various districts. It is expected to have a positive effect on matching unless vacancies fully capture this effect in the first stage of estimation. The number of small-scale entrepreneurs proxies for the presence of an important source of dynamism and jobs in the transition economies. This variable is expected to have a positive effect on matching. The ratio of the value of agricultural to industrial production in 1990 proxies for the sectoral diversity of districts at the start of the transition. The distance of the district capital from the West German or Austrian border allows us to check the widely held belief that the low unemployment in the Czech Republic is brought about by the ease with which Czech workers can participate in the German and Austrian labor markets. Population density of the district proxies for the average geographic proximity of agents in the labor market.

Within the Czech Republic, we were able to include two additional variables: the amount of government funds spent on active labor market policy programs (ALMPs) and whether the district belongs to the Sudeten lands. ALMP spending ideally captures the policies of district labor offices that are aimed at improving matching and hence reducing unemployment. ${ }^{20}$ The ALMP variable should have a positive

\footnotetext{
${ }^{20}$ Like other governments in the region, the Czech and Slovak governments introduced active labour market programs shortly after the Velvet Revolution. If these programs are successful in their objective of improving job matches and creating jobs, they should increase outflows from unemployment. For a more detailed description of these programs, see e.g., Münich and Terrell (1996) and Münich (1996).
} 
effect on job matching if higher expenditures yield more job matches and higher outflows. ${ }^{21}$ Indeed, Svejnar, Terrell and Münich (1995a) find the effect to be positive in the Czech Republic but insignificant in Slovakia, while Svejnar, Terrell and Münich (1995b) find the results to be sensitive to model specification and Burda and Lubyova (1995) find the effect to be positive in both republics. The problem is that ALMP spending may be influenced by unemployment and outflow, thus possibly causing spurious correlation between ALMP spending and outflow. Boeri and Burda (1995) instrument ALMP, using as instruments district-specific ALMP spending aggregated over the four quarters of the current year, the other regressors in the matching function, and in Slovakia also an explicit allocation rule for ALMP. As we have shown above, the unemployment and vacancy data are not strongly exogenous and the contemporaneous aggregation of ALMP may hence not be a valid instrument. As a result, we instrument current ALMP spending in a district by its lagged values and, we also test the sensitivity of estimates to the choice of other instruments.

By distinguishing Czech districts that fall into the Sudeten lands from others, we control for the different structure of this part of the Czech Republic. The Sudeten lands were depopulated after World War II as the German population was moved to West Germany. Property rights were less clearly established and more sluggish restitutions may have caused labor market adjustments in these regions to differ from the rest of the country.

\section{Basic Statistics and Econometric Estimates}

\subsection{Basic Statistics}

\footnotetext{
${ }^{21}$ One cannot take the direct effect of ALMP on outflow to be the share of total outflow going into ALMP programs, since there may be important substitution effects (regular employees being substituted by subsidized employees) and displacement effects (job losses in other firms as a result of changes in product and other markets that are brought about by the subsidized jobs). There is also a problem in that some outflow to short term public works is not consistently reported as part of outflow and the better prospect of outflow due to retraining is difficult to identify directly.
} 
As may be seen from Figure 2, between 1991 and 1994, the Czech and Slovak Republics experienced a similar pattern of unemployment growth, but the rate of increase was much steeper in Slovakia. Indeed, with the Slovak labor force being about one-half of the Czech labor force, one observes the number of unemployed in Slovakia rising to about twice the absolute level observed in the Czech lands (over 350,000 vs. less than 200,000). Moreover, while the total number of vacancies remained low $(8,000-13,000)$ in Slovakia, it gradually rose to about 100,000 in the Czech Republic. The average districtlevel statistics, reported in Appendix Table A1, provide a similar picture of a high unemployment and low vacancy economy in Slovakia versus a more balanced unemployment-vacancy situation in the Czech lands. An analysis of the underlying district-level mismatch indicates that while in the Czech Republic one finds a number of districts where the number of vacancies is similar or even exceeds the number of unemployed, in most Slovak districts the number of unemployed greatly exceeds the number of vacancies (Münich, Svejnar and Terrell, 1996).

In Figure 3 we plot the evolution of the overall relationship between the number of unemployed and number of vacancies in the two republics (the values for Slovakia are scaled by the size of the labor force so as to be comparable with those for the Czech Republic; the same scaling is also used for the Slovak flows in Figures 4 and 5). The vertical parts of the Czech and Slovak data plotted in Figure 3 relate to 1991 and depict the rapid rise of unemployment in the early phase of the transition. Since 1992, one observes negative Beveridge-type relationships between unemployment and vacancies in both republics. However, the Beveridge curve is steep in Slovakia, capturing the fact that vacancies varied little during significant unemployment fluctuations, while in the Czech Republic it is flat, reflecting the fact that vacancies increased dramatically over time, with relatively small variations in unemployment. From the Slovak plot it also appears that the Beveridge curve has been shifting outward over time, consistent with 
the hypothesis of hysteresis ${ }^{22}$ and the fact that duration of unemployment has been rising in Slovakia after the rapid rise in the unemployment rate. Finally, as may be seen from Appendix Tables A2 and A3, the negative correlation between adjusted district-level vacancies and unemployment is generally stronger in the Czech Republic than in Slovakia, with the absolute size of the correlation coefficient growing over time in Slovakia and displaying an inverted U shape pattern over time in the Czech Republic.

\subsection{Econometric Estimates}

\section{The First Stage}

Since the transition period has been characterized by a rapid and profound regime change, we have collected monthly data in order to estimate the model separately for each year and test for changes in parameter estimates over time. The earliest data are from 1991 and these are used as instruments for the 1992 regressions. The choice of calendar years as separate periods for estimation was guided by the fact that the most fundamental policy measures (e.g., the 1991 price liberalization, the 1992 change in unemployment compensation system, the 1993 value added tax, and the 1993 separation of the Czech and Slovak Republics) were all introduced on January 1 of the given years.

The tests of the form of the matching function are summarized in Table 1. The tests are based on outflow to jobs and total outflow in the Czech Republic, and on total outflow in Slovakia. As may be seen from Table 1, the results are similar in the two countries in that only the hypothesis of weak separability between $\mathrm{U}$ and $\mathrm{S}$ cannot be rejected in any year. Importantly, the usual Cobb-Douglas specification is also rejected in both republics in all years, indicating that it is imperative to allow for a more flexible functional

\footnotetext{
${ }^{22}$ The hysteresis hypothesis implies that a fall in demand is accompanied by structural changes that reduce the effectiveness of matching. Examples of these structural changes are the loss of skills among the long-term unemployed and the adjustment of firm's production practices in periods of low product demand.
} 
form than the usual Cobb-Douglas. We have also tested the validity of the frequently invoked condition of constant returns to scale. As may be seen from Table 1, like the Cobb-Douglas specification, this condition is also rejected in both republics in all years. Finally, we have checked if the estimates of returns to scale differ when one uses data that are adjusted for the size of the districts as opposed to those that are unadjusted. We have found the two sets of estimates to differ somewhat, but not excessively. An examination of the estimated ? coefficients indicates that their sum is often not significantly different from zero, thus suggesting that this may be one of the reasons for the observed similarities of the two sets of coefficients in the present study.

On the basis of the tests reported in Table 1, we have used the translog form with weak separability of $\mathrm{U}$ and $\mathrm{S}$ in further analysis. ${ }^{23}$ The estimates of matching function elasticities and returns to scale, evaluated at the geometric means of variables, are reported in Table $2 .{ }^{24}$ The estimates are again based on outflow to jobs and total outflow in the Czech Republic, and on total outflow in Slovakia. As may be seen from Table 2, the Czech estimates based on outflow to jobs and total outflows are similar, with the former showing somewhat higher point estimates of the returns to scale than the latter. The estimates are precisely estimated and they fluctuate without a trend in the region of increasing returns, ranging from 2.9 to 3.5 for outflows to jobs and 2.2 to 2.8 for total outflows. Contrary to many earlier studies, our estimates hence indicate that the matching process in the Czech Republic displays strongly increasing returns to scale. The corresponding estimates of returns to scale in Slovakia are relatively low and they are imprecisely

\footnotetext{
${ }^{23}$ The complete sets of estimated parameters for the general and weakly separable functional forms are reported for both countries in Appendix Table A4. As we mention below, in order to test if the estimated parameters of the matching function vary across the range of variable values, we have also re-estimated the matching function on Czech data using a spline function and found the results to be quite similar.

${ }^{24}$ The corresponding estimates based on the unconstrained translog model are analogous and are reported in Appendix Table A5.
} 
estimated. The point estimates are 0.2 in 1992, 0.1 in 1993, 1.4 in 1994 and 0.9 in 1995 . The 1992 and 1993 estimates are not significantly different from zero, while for 1994 and 1995 one can barely reject this hypothesis at conventional significance test levels.

The increasing returns to scale observed in the Czech Republic may be brought about by a number of factors. Our discussions with directors of the district labor offices in both republics suggest that the Czech offices have been more efficient in assisting the unemployed to find jobs. From the very start of the transition, the Czech offices were faster equipped with computers, experienced a lower turnover of key personnel, ${ }^{25}$ and were not forced to handle as large a number of unemployed as their Slovak counterparts. Another explanation of the Czech-Slovak differences in returns to scale has been advanced by Mortensen (1997), who attributes the difference to "animal spirits", or differences in beliefs of economic decisionmakers in the two republics. With the Czech and Slovak fundamentals being similar, Mortensen (1997) derives a theoretical model in which one can attribute the higher returns to scale in the Czech Republic to greater optimism of its economic agents. While it is difficult to provide direct evidence on differences in animal spirits, we find Mortensen's explanation plausible. As HST (1998) document, in the early 1990s the Czech Republic registered a faster growth of small scale (private sector) firms than Slovakia, attracted about five times as much foreign investment per capita, launched faster privatization of state owned firms, and was less hit by the decline in military production. In the early 1990s, the expectation that the Czech economy would outperform the Slovak economy was so widespread that in 1992 it led to the election of a strongly pro-reform government in the Czech Republic and a much more gradualist (socially-oriented) government in Slovakia. The different orientation of the two governments contributed to the decision to

\footnotetext{
${ }^{25}$ Many directors of the Slovak district labor offices were replaced concomitantly with changes in governments during the early to mid 1990s.
} 
split Czechoslovakia in 1993. Finally, as may be seen from Table 1, in both the Czech Republic and Slovakia the chi-square test allows us to reject the hypothesis of equality of returns to scale in consecutive years at conventional test levels.

A comparison of the individual elasticity estimates in Table 2 indicates that vacancies and the newly unemployed play a much more important part in the Czech Republic than in Slovakia. The Czech estimates based on outflow to jobs and total outflow are again similar and they yield vacancy elasticities that are all significantly different from zero and range from 0.7 to 1.2 . In contrast, the estimated vacancy elasticities in Slovakia range from zero to 0.2 and only the 1993 estimate of 0.2 is significantly different from zero.

The relative part played in matching by the newly unemployed (the inflow) is analogous to that played by vacancies. The estimated elasticities in the Czech Republic are all positive, significantly different from zero and ranging from 0.4 to 0.9 . In Slovakia, they are all close to and not significantly different from zero. Hence, the newly unemployed match with vacancies in the Czech Republic, but not in Slovakia.

Finally, the estimated elasticities of the existing unemployed are high and statistically significant in the Czech Republic, ranging from 1.0 to 1.9. The Slovak estimates are statistically insignificant in 1992 and 1993, and rise to 1.3 in 1994 and 0.9 in 1995. The latter two estimates are significantly different from zero and not significantly different from one another. The existing unemployed have thus in all years been an important determinant of outflow in the Czech Republic and since 1994 also in Slovakia.

As our results indicate, the labor demand side of the matching process, as proxied by vacancies, has been much weaker in Slovakia than the Czech Republic during the transition. Indeed, while vacancies have been an important component of the matching process in the Czech Republic, in Slovakia vacancies appear to have been an insignificant factor. Moreover, while the Czech matching function was relatively stable between 1992 and 1995, the Slovak one developed from having basically insignificant parameters 
in 1992 and 1993, to becoming more structured in 1994 and 1995.

The different results for the Czech and Slovak republics raise the issue of whether the matching technology is different in high and low unemployment districts. In particular, while the Czech observations cover a wide variety of unemployment-vacancy combinations, the Slovak districts reflect primarily low vacancy-high unemployment combinations. As a result, in order to assess whether high unemployment low vacancy districts in the Czech Republic have similar matching technology as those in Slovakia, we have re-estimated the matching function using only data from the half of the Czech districts with higher unemployment-vacancy ratio. In the context of theories of multiple equilibria, this allows us to test the hypothesis that increasing returns in matching do not result from a higher intensity of search, as suggested by Mortensen (1997), but are brought about by a higher intensity of hiring when local unemployment is low (i.e., when the opportunity cost to employers of not hiring is high). The estimates indicate that increasing returns to scale are observed even in high unemployment-low vacancy districts of the Czech Republic -- the estimated returns to scale (standard errors) are 3.06 (.358) for 1992, 3.74 (.423) for 1993, 3.14 (.463) for 1994 and 3.08 (.459) for 1995. The results hence suggest that the increasing returns are more consistent with multiple equilibria theories based on concepts such as high intensity of search than high intensity of hiring.

We have also checked if our results are sensitive to imposing the same functional form in all ranges of the data by estimating the Czech matching function using Suit et al.'s (1978) approach to the spline function. ${ }^{26}$ The estimation, which constrains the coefficients to be the same throughout the $1992-95$ period,

\footnotetext{
${ }^{26}$ In Slovakia, where the number of observation is much smaller, it was difficult to identify this model.
} 
confirms our earlier results in that it yields similar overall values of parameters and returns to scale. ${ }^{27}$

\section{The Second Stage}

The estimated effects on matching of the structural and policy variables that are time invariant or measured only with annual frequency are reported in Table 3 . We report estimates from four representative specifications since some of the estimates are a bit sensitive to the inclusion of particular variables. Because the number of estimates is large and the outflow to jobs and total outflow estimates for the Czech Republic are again very similar, we report only the estimates for outflow to jobs.

As may be seen from Table 3, in the Czech Republic the proportion of university educated individuals in the district unemployment pool increases the efficiency in matching in all years, while in Slovakia the effect only becomes positive in 1994 and 1995, after being negative in 1992 and 1993. In contrast, the proportion of unemployed with high school education is found to increase matching efficiency in all the specifications in Slovakia in 1992, 1993 and 1995, as well as in about one-half of the specifications in 1994, while it has an insignificant or negative effect in the Czech Republic. Hence, while the two republics have a similar educational structure of the population, the matching process appears to favor more the university educated in the Czech Republic and those with high school education in Slovakia.

In both countries, the long-term (more than nine months) unemployed have a negative effect on the efficiency of matching in almost all specifications and years. This effect has a much greater magnitude in Slovakia, where the problem of long-term unemployment has been more acute. Factors such as scarring and loss of skills of the long-term unemployed are hence important in the matching process.

\footnotetext{
${ }^{27}$ Constraining the coefficients to be identical over time is consistent with Profit's (1997) nonparametric study in which he identifies bi-modality and persistence of two unemployment equilibria in the Czech data from 1991 and 1994.
} 
The prevalence of small enterprises has a positive effect on matching in Slovakia in 1992, but the effect becomes insignificant in the later years. In the Czech Republic the coefficient is significant in the more parsimonious specifications of 1993-95, yielding a positive effect in 1994 and 1995, but a negative effect in 1993. Small enterprises are sometimes viewed as a source of extra job opportunities because they engage in labor-intensive activities. Our results indicate that this effect, if present, does not manifest itself systematically as an increase in the efficiency of matching of the unemployed and vacancies.

In the Czech Republic, where ALMP expenditure data are available, we have estimated the effect of ALMPs on the efficiency of matching, using at first the previous year's value of ALMP expenditure as an instrument. As can be seen from the table, the amount of ALMP spending is found to have had an insignificant effect on the efficiency of matching in 1992, a positive effect in 1993 and negative effects in 1994 and 1995. These estimates suggest that the effect of government's ALMP expenditures was insignificant in the early stages of the transition, became positive in 1993 and actually hindered the matching process in the more mature transition phase of the mid 1990s. Since lagged ALMP might include some spurious correlation, we have also estimated the effect of ALMPs using other instruments. ${ }^{28}$ First, we used as instruments the share of votes obtained by the governing coalition of political parties (districts voting in favor of the coalition might be expected to get more ALMP funds because the funds are allocated by the central government), the share of unemployed who are within 0-3 months before the expiration of their unemployment benefits (ALMP funds are often allocated preferentially to those who lose their entitlement to unemployment benefits) and the share of high-school graduates in the total population of

\footnotetext{
${ }^{28}$ Since our inquiries with officials at the district labor offices indicated that ALMP funds were distributed with a view toward the unemployment and vacancy situation in the individual districts, we wanted to ensure that our instrument did not pick up the likely positive effect of local unemployment on the allocation of ALMP expenditures.
} 
their age cohort (a significant portion of ALMP funds is in employment subsidies for school leavers). We found the correlation of these three instruments with ALMP spending to be very low, however, and their addition to the set of instruments had a negligible effect on the estimated coefficients. ${ }^{29}$ We next used as an instrument the part of district-level ALMP expenditures that could not be explained by local unemployment rate and vacancies. The unexplained residual portion of ALMP expenditures may for instance reflect the relationship (influence) that the director of the district labor office has with the central ALMP budget office, and that is unrelated to the situation in the local labor market. In this specification, we found the ALMP expenditure coefficient to be statistically insignificant. Finally, we have performed the analysis using as instruments variables that capture the structure of district-level agencies (such as the per capita number of primary schools, teachers and government agencies) that could be correlated with the allocation of the budget among various expenditure categories, including ALMP, and are likely to be independent of the local labor market conditions. These specifications generally also yielded insignificant effects of ALMP. In view of the in-depth nature of our investigation, we conclude that the effect of ALMP expenditures on matching efficiency has most likely been insignificant.

The remaining variables produce insignificant or only occasionally significant coefficients. The extent of agriculture in the district at the start of the transition process has no effect on matching in Slovakia and, with the exception of 1993 when it is negative, the effect is also insignificant in the Czech Republic. The level of industrial production, population density, distance to a western border, and the location of a district in the Sudeten lands have no effect on the efficiency of matching. The observed insignificance of these variables suggests that the importance that has been attributed to them in popular

\footnotetext{
${ }^{29}$ The highest correlation coefficient, -.19, was that for the correlation of spending with the share of votes cast for central government coalition.
} 
policy discussions about the low unemployment in the Czech Republic is unfounded from the standpoint of matching efficiency.

\section{Concluding Observations}

After being non-existent under communism, the unemployment rate in all Central and East European countries except for the Czech Republic rose to double digit rates and was coupled with long unemployment durations in the early and mid 1990s. The very low unemployment in the Czech Republic was in large part brought about by a high outflow rate from unemployment. In our analysis, we have compared the nature and determinants of Czech Republic's outflow from unemployment to that of its traditional counterpart republic, Slovakia. This comparison brings us as close as possible to analyzing a controlled experiment. Until 1993, the two republics shared the same currency, legal system and institutional framework. Moreover, except for unemployment, their aggregate economic indicators were similar. Yet, the Slovak labor market indicators resembled those of Poland, Hungary and other CEE economies rather than those of the Czech Republic. The Czech-Slovak comparison is hence useful per se as well as for understanding the difference between the Czech experience and that of other economies in the region. Our analysis points to the importance of the following factors.

In the early 1990s, the Czech and Slovak republics experienced a similar pattern of unemployment growth, but the rate of increase was much steeper in Slovakia than in the Czech lands. Moreover, while the total number of vacancies remained at a low level in Slovakia, it gradually rose to a high level in the Czech Republic. One hence observes a high unemployment-low vacancy economy in Slovakia versus a more balanced unemployment-vacancy situation in the Czech lands. At the district-level one finds a number of districts in the Czech Republic where the number of vacancies is similar or even exceeds the number of unemployed, while in most Slovak districts the number of unemployed greatly exceeds the number of 
vacancies.

In the context of the literature on matching functions, we reject the usual Cobb-Douglas specification and the hypothesis of constant returns to scale in favor of a translog matching function with weak separability between the existing and newly unemployed. The Czech data generate strong increasing returns to scale throughout the 1992-95 period, while the Slovak data point to low returns in 1992-93 and somewhat higher returns in 1994-95. An important part of our explanation of the Czech-Slovak differences hence lies in the much higher returns to scale in matching in the Czech Republic than in Slovakia, especially in the crucial early period of the transition. In the context of the macroeconomic literature, this points to the possible existence of multiple equilibria. In particular, Mortensen (1997) interprets our findings as indicative of greater optimism and search intensity in the Czech Republic than in the Slovak Republic.

Our theoretical analysis suggests that by not adjusting data for the varying size of districts or regions, previous studies may have generated estimates of the returns to scale of the matching function that were biased toward unity. Our empirical estimates in turn indicate that vacancies and the newly unemployed have played a much more important part in the matching process in the Czech Republic than in Slovakia. The demand side of the matching process, as proxied by vacancies, has thus been much weaker in Slovakia than the Czech Republic. In fact, while matching between the unemployed and vacancies was important in the Czech Republic, in Slovakia vacancies appear to have been an insignificant factor.

Our estimates indicate that the process of outflow from unemployment in the Czech Republic was relatively stable between 1992 and 1995, while in Slovakia the process developed from having virtually insignificant parameters in 1992 and 1993 to being driven by the number of unemployed in 1994 and 1995.

Only few of the structural-policy variables generate systematic effects on matching. The long-term 
unemployed have a negative effect on the efficiency of matching, with the effect being much greater in Slovakia, where the problem of long-term unemployment has been acute. Education of the unemployed has a systematic effect but it varies across the republics. Finally, the effects of expenditures on active labor market policies on the efficiency of matching is statistically insignificant in most specifications. Our estimates hence question the findings of a positive effect of ALMP that were based on OLS estimates or weakly exogenous instrumental variables and did not control for the functional form of the matching function or size of districts.

Overall, our study suggests that the exceptionally low unemployment rate in the Czech Republic as compared to Slovakia and the other CEE economies has been brought about principally by the following phenomena in the Czech Republic: (1) a rapid increase in vacancies along with unemployment, resulting in a relatively balanced unemployment-vacancy situation at the aggregate as well as district level, (2) a major part played by vacancies and the newly unemployed in the outflow from unemployment, (3) a matching process with strongly increasing returns to scale throughout (rather than only in parts of) the transition period, and (4) ability to keep the long term unemployed at relatively low levels. Since until 1996 the Czech economy registered overall economic growth that was similar to that of the neighboring high unemployment economies (e.g., Hungary, Poland and Slovakia), the interesting question, to be addressed in future research, is whether the Czech Republic's favorable vacancy situation, coupled with its strong matching process, was brought about by a relatively high level of initial economic activity (better initial conditions) or a relatively delayed restructuring of firms. 


\section{$\underline{\text { Appendix I }}$}

Transforming equation (2) into mean deviations, we obtain the following form:

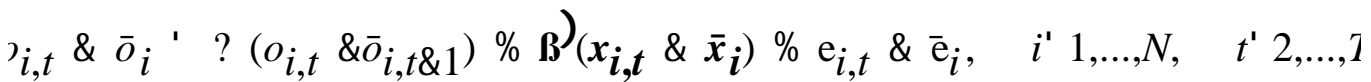
where

$$
\begin{gathered}
\bar{o}_{i}{ }^{\prime} \frac{1}{T \& 1} \mathrm{j}_{t^{\prime}}^{T} o_{i, t}, \quad \bar{o}_{i, t \& 1}{ }^{\prime} \frac{1}{T \& 1} \mathrm{j}_{t^{\prime} 1}^{T \& 1} o_{i, t}, \\
\bar{x}_{i}{ }^{\prime} \frac{1}{T \& 1} j_{t^{\prime} 2}^{T} x_{i, t}, \quad \overline{\mathrm{e}}_{i}{ }^{\prime} \frac{1}{T \& 1} \mathrm{j}_{t^{\prime} 2}^{T} \mathrm{e}_{i, t} .
\end{gathered}
$$

and where the letters denote logs of variables and input factors $X^{\prime} s$ are stacked in vector $\boldsymbol{x}_{i, t}$. Each districtspecific mean of outflow, $\bar{o}_{i, t-1}$, incorporates all $T-1$ error terms $\mathrm{g}_{, t}$ that are specific to a given district $i$. The necessary assumption of independence of the error and explanatory variables is therefore explicitly violated in partial adjustment models. Balestra and Nerlove (1967), Maddala (1971), Nickell (1981), and Arellano and Bond (1991) provide detailed evidence on the size and sign of biases of both ? and \$ in experimental settings. For ? $>0$, the bias in $?$ is negative and decreases with $T$, it is not approaching zero as $?=0$, and it is larger if other right hand side variables are included. Moreover, the bias in $\beta$ is positive if other right hand side variables are positively related to lagged values $o_{i, t-1}$.

\section{$\underline{\text { Appendix II }}$}

Equation (2) transformed into deviations from forward means has following form:

$$
o_{i, t}^{(} ? o_{i, t \& 1}^{(} \% \boldsymbol{B x} \underset{i, t}{(} \% \mathrm{e}_{i, t}^{(}
$$

where

$$
\begin{gathered}
o_{i, t}^{(}, \quad o_{i, t} \& \frac{1}{1 \% T_{F}}\left(o_{i, t} \% o_{i, t} \% \text { \% } \% \% o_{i, t \& 1} \%_{F}\right) \\
o_{i, t \& 1}^{(} \quad o_{i, t \& 1} \& \frac{1}{1 \% T_{F}}\left(o_{i, t \& 1} \% o_{i, t} \% \ldots \% o_{i, t \& 1} \% \Phi_{F}\right)
\end{gathered}
$$




$$
\begin{aligned}
& x_{i, t}^{(}, x_{i, t} \& \frac{1}{1 \% T_{F}}\left(x_{i, t} \% x_{i, t} \% \% \ldots \% x_{i, t} \% \boldsymbol{d}_{F}\right) \\
& \mathrm{e}_{i, t}^{(}, \mathrm{e}_{i, t} \& \frac{1}{1 \% T_{F}}\left(\mathrm{e}_{i, t} \% \mathrm{e}_{i, t} \% \% \ldots \% \mathrm{e}_{i, t} \% d_{F}\right)
\end{aligned}
$$

The appropriate instruments are computed as deviations from backward means as

$$
\begin{aligned}
& o_{i, t \& 1}^{I V}{ }^{\prime} \quad o_{i, t \& 1} \& \frac{1}{T_{B}}\left(o_{i, t \& 1} \% o_{i, t \& 2} \% \ldots \% o_{i, t \& T_{B}}\right) \\
& o_{i, t \& 2}^{I V} o_{i, t \& 2} \& \frac{1}{T_{B}}\left(o_{i, t \& 2} \% o_{i, t \& 3} \% \ldots \% o_{i, t \& 1 \& T_{B}}\right)
\end{aligned}
$$

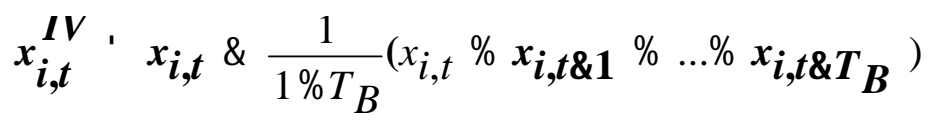

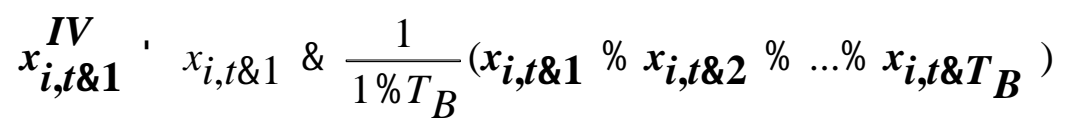

The transformed error term $\mathrm{g}_{i, t}^{*}$ incorporates all terms $\mathrm{g}_{, v} \mathrm{~g}_{t, t+1}, \ldots, \mathrm{g}_{, t+T F}$ and the transformed right hand side

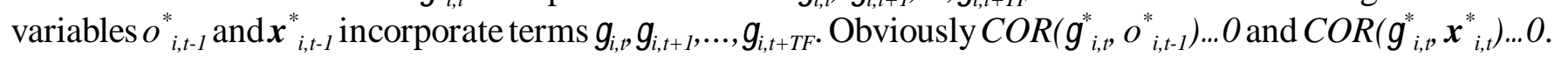
Instruments $o^{I V}{ }_{i, t-1}, o^{I V}{ }_{i, t-2}$ and $x^{I V}{ }_{i, t-2}$ incorporate terms $\mathrm{g}_{t, t-1}, \mathrm{~g}_{t,-2}, \ldots, \mathrm{g}_{t,-T B}$. The instruments are not correlated with forward errors $\mathrm{g}_{i t}, \mathrm{~g}_{, t+1}, \ldots, \mathrm{g}_{t+T F}$ and therefore $\operatorname{COR}\left(\mathrm{g}_{i, p}^{*}{ }^{*}{ }_{i, t-1}\right)=0$ and $\operatorname{COR}\left(\mathrm{g}_{i, t}^{*} \boldsymbol{x}^{I V}{ }_{i, t}\right)=0$. Having $T$ crosssections we could in principle increase the set of instruments with $t$ (Holtz-Eakin 1988, Arrelano and Bond, (1991). Since the explanatory power of instruments of farther lags is small, we limit the number of lags used as instruments to three.

\section{$\underline{\text { Appendix III }}$}

Partial derivatives of equation (2) give us elasticities of matching with respect to the number of unemployed, inflow into unemployment and vacancies. The elasticities are given as:

$$
?_{u}{ }^{\prime} \quad \beta_{u} \% ? ?_{u u} \ln X_{u} \% ? u s \ln X_{s} \% ? u v \ln X_{v}
$$




$$
\begin{gathered}
?_{s}{ }^{\prime} \quad B_{s} \% ?_{s s} \ln X_{s} \% ?_{u s} \ln X_{u} \% ?_{s v} \ln X_{v} \\
?_{v}{ }^{\prime} \quad \beta_{v} \% ?_{v v} \ln X_{v} \% ?_{u v} \ln X_{u} \% ?_{s v} \ln X_{s}
\end{gathered}
$$

and they vary with explanatory variables rather than being constants as in the case of the Cobb-Douglas specification. The elasticity of scale ? is given by:

$$
?^{\prime} ?_{u} \% ?_{s} \% ?_{v}
$$

Substituting the expressions for elasticities into the formula for returns to scale and rearranging yields

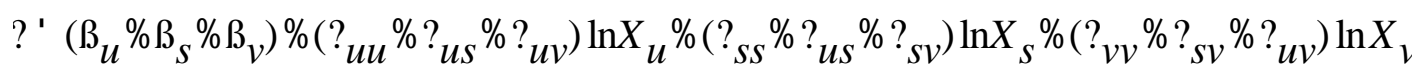

Since constant returns to scale must hold independently of the values of the explanatory variables, the following linear parameter restrictions have to be satisfied:

$$
\begin{gathered}
\beta_{u} \% \beta_{s} \% \beta_{v}{ }^{\prime} 1 \\
?_{u u} \% ?_{u s} \% ?_{u v}{ }^{\prime} 0 \\
?_{s s} \% ?_{u s} \% ?_{s v}{ }^{\prime} 0 \\
?_{v v} \%{ }_{u v} \% ?_{s v}, 0
\end{gathered}
$$

\section{Appendix IV}

\section{a) The Spurious Scale Effect}

For the purposes of exposition, we present a simple case that demonstrates the impact of the spurious scale effect on estimation. Assume that the country is a homogeneous territory divided administratively into districts of different sizes with identical labor market conditions and characterized by a simple Cobb-Douglas matching function with increasing returns to scale $\left(\beta_{u}+\beta_{v}>1\right)$. As a result of homogeneity, the outflow, 
unemployment and vacancies in each district, $O_{i} U_{i}$ and $V_{i}$, are proportional to national aggregates $O, U$, and $V$

$$
O_{i}=l_{i} O, U_{i}=l_{i} U, \text { and } V_{i}=l_{i} V,
$$

where $l_{i}$ is the share of district $i$ in the national labor force, defined as $L_{i} / L \cdot{ }^{30}$ Not taking the district size into account and estimating the matching function on unadjusted cross-sectional data amounts to estimating the model

$$
\ln O_{i}{ }^{\prime} \quad \text { a } \% \beta_{u} \ln U_{i} \% \beta_{v} \ln V_{i} \% \mathrm{e}_{i}
$$

Substituting (34) into (35), we get

$$
\ln \left(l_{i} O\right)^{\prime} \text { a } \% \beta_{u} \ln \left(l_{i} U\right) \% \beta_{v} \ln \left(l_{i} V\right)
$$

which in turn yields

$$
\ln l_{i}{ }^{\prime}\left(\beta_{u} \% \beta_{v}\right) \ln l_{i} \%\left(\mathrm{a} \& \ln O \% \beta_{u} \ln U \% \beta_{v} \ln V\right) \% \mathrm{e}_{i}
$$

It is obvious that the estimation of (38) is identical to estimating (36). However, (38) represents a regression of $l_{i}$ on itself plus a constant term. It will hence generate constant returns to scale $\left(\beta^{\wedge}{ }_{u}+\beta^{\wedge}{ }_{v}=1\right)$ and a zero constant term $\left(\hat{a}=\ln O-\beta^{\wedge}{ }_{u} \ln U-\beta^{\wedge}{ }_{v} \ln V\right)$. The estimation of model (36) therefore yields biased estimates since we have postulated increasing returns to scale.

A remedy for the problem is to adjust the variables by the district size in order to obtain the following model:

$$
\ln \left(\frac{O_{i}}{L_{i}}\right){ }^{\prime} \quad \text { а } \% \beta_{u} \ln \left(\frac{U_{i}}{L_{i}}\right) \% \beta_{v} \ln \left(\frac{V_{i}}{L_{i}}\right) \% \mathrm{e}_{i}
$$

which can be rearranged as

$$
\ln O_{i}{ }^{\prime} \quad \text { а } \% \beta_{u} \ln U_{i} \% \beta_{v} \ln V_{i} \%\left(\beta_{u} \% \beta_{v} \& 1\right) \ln L_{i} \% \mathrm{e}_{i}
$$

A comparison of the adjusted model (39) to the unadjusted model (35) indicates that they are equivalent if and only if at least one of the two following conditions is satisfied:

(i) $\beta_{u}+\beta_{v}-1=0$ (the underlying matching displays constant returns to scale)

\footnotetext{
${ }^{30}$ Note that for expositional purpose the variance in district level variables is brought about completely by the administrative variation in district sizes rather than by economic factors.
} 
(ii) $\operatorname{Cor}\left(\ln L_{i}, \ln U_{i}\right)=\operatorname{Cor}\left(\ln L_{i}, \ln V_{i}\right)=0$.

In our example, neither condition is satisfied because (i) we are assuming increasing returns to scale $\left(\beta_{u}+\beta_{v}-1>0\right)$ and (ii) $U_{i}=U L / L$ and $V_{i}=V L / L$, resulting in $\operatorname{Cor}\left(\ln L_{i}, \ln U_{i}\right)=\operatorname{Cor}\left(\ln L_{i}, \ln V_{i}\right)=1$.

In general, one has no a priori information about the returns to scale since they represent a statistic that is to be estimated from the data. The intercorrelations among the unadjusted variables can of course be checked in advance. Judging from the Czech and Slovak data at our disposal, these intercorrelations are positive and significant.

\section{b) Data Transformations, Functional Form and the Spurious Scale Effect}

When the district size does not change over time, a fixed effects transformation eliminates the spurious scale effect in a Cobb-Douglas but not translog functional forms of the matching function.

A fixed effects (first difference) transformation of the adjusted equation (40) leads to

$? \ln O_{i, t} \& ? \ln L_{i, t}{ }^{\prime} \quad \beta_{u} ? \ln U_{i, t \& 1} \% \beta_{v} ? \ln V_{i, t \& 1} \%\left(\beta_{u} \% \beta_{v}\right) ? \ln L_{i, t \& 1}$

If the size variable $L_{i}$ is constant over time, (41) can be simplified to yield

$$
? \ln O_{i, t}{ }^{\prime} \quad \beta_{u} ? \ln U_{i, t \& 1} \% \beta_{v} ? \ln V_{i, t \& 1}
$$

Equation (42) is identical to a fixed effects transformation of the unadjusted model (36). There is hence no need to adjust variables if $L_{i}$ is constant over time and a fixed effects transformation is used together with a Cobb-Douglas specification of the matching function.

The mis-specification caused by the spurious scale effect remains even with fixed effects and constant $L_{i}$ if the true form of the matching function is more general than Cobb-Douglas, as in our case of a translog specification with three inputs. Such a model may be written in an adjusted form as

$$
\ln \left(\frac{O_{i}}{L_{i}}\right)^{\prime} \quad{ }_{k^{\prime}}^{\mathrm{j}}{ }_{u, s, v} \beta_{k} \ln \left(\frac{X_{k, i}}{L_{i}}\right) \% .5{ }_{k^{\prime}}{ }^{\mathrm{j}} u, s, v \quad l^{\prime}{ }_{u, s, v} ?_{k l} \ln \left(\frac{X_{k, i}}{L_{i}}\right) \ln \left(\frac{X_{l, i}}{L_{i}}\right)
$$


Decomposing the logarithms of adjusted variables and rearranging individual terms, one obtains

$$
\begin{aligned}
& \ln O_{i} \& \ln L_{i}{ }^{\prime} \\
& k^{\prime}{ }_{u, s, v}^{\mathrm{j}} \beta_{k} \ln X_{k, i} \% .{ }_{k^{\prime}}^{\mathrm{j}} u, s, v \quad l^{\prime}{ }_{u, s, v}^{\mathrm{j}} ?_{k l} \ln X_{k, i} \ln X_{l, i} \% \\
& \ln _{k^{\prime}}{ }_{u, s, v} B_{k} \% \ln L_{k^{\prime}}{ }_{u, s, v} \ln X_{k, i} l^{\prime}{ }_{u, s, v} ?_{k l} \% \\
& .5\left(\ln L_{i}\right)^{2}{ }_{k^{\prime}} \mathrm{j}_{u, s, v} l^{\prime}{ }_{u, s, v}^{\mathrm{j}} ?_{k l}
\end{aligned}
$$

and applying the fixed effects transformation by first differencing yields

$$
\begin{aligned}
& ? \ln O_{i} \& ? \ln L_{i}{ }^{\prime} \\
& k^{\prime}{ }_{u, s, v}^{\mathrm{j}} \beta_{k} ? \ln X_{k, i} \% .5{ }_{k^{\prime}}^{\mathrm{j}}{ }_{u, s, v} l^{\prime}{ }_{u, s, v}^{\mathrm{j}} ?{ }_{k l} ?\left(\ln X_{k, i} \ln X_{l, i}\right) \%
\end{aligned}
$$

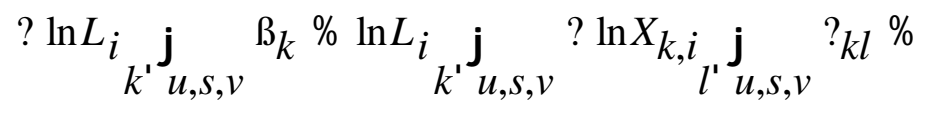

$$
\begin{aligned}
& .5 ?\left(\ln L_{i}\right)^{2}{ }_{k^{\prime}} \mathrm{j}_{u, s, v} l^{\prime}{ }_{u, s, v}^{\mathrm{j}} ?{ }_{k l}
\end{aligned}
$$

Since the district size is constant over time, first differencing cancels out several terms and (44) becomes

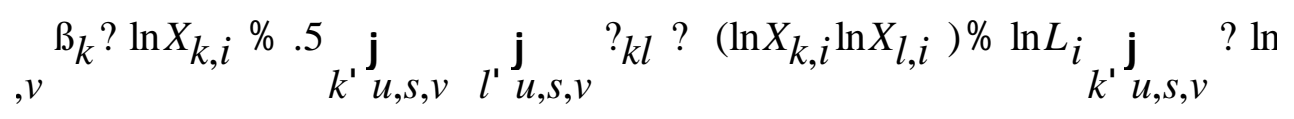

Expanding the sum operator and grouping the terms by input factors yields

$$
\begin{gathered}
? \ln O_{i}{ }^{\prime} \\
{\left[\beta_{u} \& L_{i}\left(?_{u u} \% ?_{u s} \% ?_{u v}\right)\right] ? \ln X_{u, i} \%} \\
{\left[\beta_{s} \& L_{i}\left(?_{s s} \% ?_{u s} \% ?_{s v}\right)\right] ? \ln X_{s, i} \%} \\
{\left[\beta_{v} \& L_{i}\left(?_{v v} \% ?_{u v} \% ?_{v s}\right)\right] ? \ln X_{v, i} \%} \\
.5{ }_{k}{ }^{\prime}{ }_{u, s, v} l^{\prime}{ }_{u, s, v}{ }_{k l} ? \ln X_{k, i} \ln X_{l, i}
\end{gathered}
$$

Equation (46) resembles the unadjusted specification. The direct effect parameters enter as a sum of the original coefficients $\beta \mathrm{s}^{\prime}$ minus the product of $L_{i}$ and the sum of cross-effect parameters ?s'. Moreover, the 
sum of the cross-effect parameters is identical with left hand side of constraints (31)-(33). It follows that the spurious size effect disappears and the fixed effects transformation of the unadjusted specification is identical with the adjusted one only when these constraints are satisfied. ${ }^{31}$ Since one knows nothing about the fulfilment of these constraints in advance, any test of returns to scale based on coefficient estimates from an unadjusted specification of the matching function is likely to yield biased estimates.

${ }^{31}$ Constraint (30) is not binding here, since it was removed by the fixed effects transformation as in the case of the simple Cobb-Douglas specification. 


\section{REFERENCES}

Anderson, T.W. and Ch. Hsiao, "Formulation and Estimation of Dynamic Models Using Panel Data," Journal of Econometrics, 18 (1982), 47-82.

Arellano, M. and S. Bond, "Some Tests of Specification for Panel Data: Monte Carlo Evidence and an Application to Employment Equations," Review of Economic Studies, 58 (1991), 277-297.

Balestra, P. and M. Nerlove, "Pooling Cross Section and Time Series Data in the Estimation of a Dynamic Model: The Demand for natural Gas," Econometrica, 34 (3) (1967), July, 585-612.

Blanchard, O. and P. Diamond, "The Beveridge Curve", Brookings Papers on Economic Activity, 1 (1989), 1-60.

Boeri, T., "Labour Market Flows and the Persistence of Unemployment in Central and Eastern Europe." in OECD (ed.) Unemployment in Transition Countries: Transient or Persistent?, (Paris: OECD, 1994), 1356.

Boeri, T. and S. Scarpetta, "Emerging Regional Labour Market Dynamics in Central and Eastern Europe," in OECD (ed.), The Regional Dimension of Unemployment in Transition Countries, (Paris: OECD, 1995), 75-87.

Boeri, T. and M. Burda, "Active Labour Market Policies, Job Matching and the Czech Miracle," CEPR Discussion Paper No. 1302, 1995.

Burda, M., "Unemployment, labour markets and structural change in Eastern Europe." Economic Policy, 16 (1993), 101-137.

Burda, M. and M. Lubyova, "The Impact of Active Labour Market Policies: A Closer Look at the Czech and Slovak Republics," in D.Newbery (ed.), Tax and Reform in Central and Eastern Europe, (London: CEPR, 1995), 173-205.

Coles,M.G. and E.Smith, "Marketplaces and Matching", CEPR Discussion Paper No.1048, 1994.

Denny, M. and M.Fuss, "The Use of Approximation Analysis to test for Separability and the Existence of Consistent Aggregates," American Economic Review, 67(3) (June 1977), 404-418.

Dyba, K. and J. Svejnar, "Stabilization and Transition in Czechoslovakia." in Blanchard O., K. Froot and J. Sachs eds. The Transition in Eastern Europe, (Chicago: University of Chicago Press, 1994), 93-122.

Dyba, K. and J. SVEJNAR, "A Comparative View of Economic Developments in the Czech Republic," Chapter 2 in Svejnar, J. The Czech Republic and Economic Transition in Eastern Europe, (Academic Press, 1995), 21-45.

Ham, J., J. Svejnar and K. Terrell, "Unemployment and the Social Safety Net During Transitions to a Market Economy: Evidence from the Czech and Slovak Republics," forthcoming, American Economic Review, December, 1998. 
Holtz-Eakin, D., "Testing for Individual Effects in Autoregressive Models", Journal of Econometrics, 39 (1988), 297-307.

Hsiao, Ch., Analysis of panel data, (Cambridge: Cambridge University Press, 1986).

Lubyova, M. and J.Ours, "The Matching Process in Labour Markets in Transition," East (Vienna: IHS European Working Paper Series, 13, 1994.

Mortensen, D. T., "Can 'Animal Spirits' Explain Czech-Slovak Unemployment Differences," paper presented at William Davidson Institute Conference on Labor Markets in Transition Economies, Ann Arbor, MI, October 17-19, 1997.

Münich, D., "Efficiency in the Implementation of the Active Employment Policy: The Case of the Czech Republic", Unpublished dissertation thesis (1998).

Münich, D., J Svejnar and K. Terrell, "The Worker-Firm Matching in the Transition: (Why) Are the Czechs More Successful than Others?” The William Davidson Institute Working Paper No. 107, October, 1997.

Münich, D. and K. Terrell, "An Overview of Labour Market Policies in the Slovak Republic", proceedings from OECD technical workshop What we can learn from the experience of transition countries with labour market policies?, (Paris: OECD 1996).

Nickell, S., "Biases in Dynamic Models with Fixed Effects," Econometrica, 49 (6) (November 1981), 1417-26.

Paukert, L., "Economic transition and women's employment in four Central European countries, 19891994,” Labour Market Paper No. 7, International labour Office, Geneva, 1995

Pissarides, C.A. Equilibrium Unemployment Theory, (Oxford: Basil Blackwell, 1992).

Profit, S. (1997), "Twin Peaks in Regional Unemployment and Returns to Scale in Job-Matching in the Czech Republic,” Discussion paper No. 63, Humboldt University, Berlin.

Schaffer, M., "Government Subsidies to Enterprises in Central and Eastern Europe: Budgetary subsidies and Tax Arrears," CEPR Discussion Paper No. 1144, March 1995.

Storer, P. "Unemployment Dynamics and Labour Market Tightness: An Empirical Evaluation of Matching Function Models," Journal of Applied Econometrics, 9 (1994), 389-419.

Suit, D.B., A. Mason and L. Chan, "Spline Functions Fitted by Standard Regression Methods," Review of Economics and Statistics, 6(1), (1978), 132-139.

Svejnar, J., K. Terrell and D. Münich, "Unemployment in the Czech and Slovak Republics," Chapter 13 in Svejnar, J.(ed.) The Czech Republic and Economic Transition in Eastern Europe, (Academic Press, 1995a), 285-316.

Svejnar, J., K. TERRELL and D. Münich, "Regional and Skill Mismatch in the Czech and Slovak 
Republics," in S. Scarpetta and A. Worgotter (eds.) The Regional Dimension of Unemployment in Transition Countries -- A Challenge for Labour Market and Social Policies, (Paris: OECD 1995b).

Warren, R.S., "Returns to Scale in a Matching Model of the Labor market," Economic Letters, 50(1) (January 1996). 
Table 1: Tests of the Functional Form of the Matching Function and Stability of Parameters over Years

Czech Republic - Outflows to Jobs

\begin{tabular}{|c|c|c|c|c|c|c|c|c|}
\hline Year & \multicolumn{2}{|c|}{1992} & \multicolumn{2}{|c|}{1993} & \multicolumn{2}{|c|}{1994} & \multicolumn{2}{|c|}{1995} \\
\hline Test & $\chi^{2}$ & $P$-value & $\chi^{2}$ & $P$-value & $\chi^{2}$ & $P$-value & $\chi^{2}$ & $P$-value \\
\hline 1.Hypothesis ${ }^{1)}-\chi^{2}(1)$ & 2.45 & 0.1173 & 0.16 & 0.6852 & 1.62 & 0.2030 & 0.25 & 0.6196 \\
\hline 2.Hypothesis ${ }^{2)}-\chi^{2}(2)$ & 10.23 & 0.0060 & 5.64 & 0.0595 & 9.47 & 0.0088 & 2.84 & 0.2423 \\
\hline 3.Hypothesis ${ }^{3)}-\chi^{2}(5)$ & 30.26 & 0.0000 & 22.00 & 0.0005 & 19.89 & 0.0013 & 33.20 & 0.0000 \\
\hline 4.Hypothesis ${ }^{4)}-\chi^{2}(6)$ & 32.09 & 0.0000 & 37.30 & 0.0000 & 20.29 & 0.0025 & 34.94 & 0.0000 \\
\hline 5.Hypothesis ${ }^{5)}-\chi^{2}(4)$ & 28.32 & 0.0000 & 58.04 & 0.0000 & 20.00 & 0.0005 & 25.37 & 0.0000 \\
\hline 6.Hypothesis ${ }^{6)}-\chi^{2}(10)$ & n.a. & n.a. & 36.90 & 0.0000 & 55.74 & 0.0000 & 23.76 & 0.0082 \\
\hline Durbin's h & 0.45 & 0.3270 & 0.59 & 0.2770 & 1.06 & 0.1450 & 1.12 & 0.1320 \\
\hline
\end{tabular}

Czech Republic - Total Outflows

\begin{tabular}{|c|c|c|c|c|c|c|c|c|}
\hline Year & \multicolumn{2}{|c|}{1992} & \multicolumn{2}{|c|}{1993} & \multicolumn{2}{|c|}{1994} & \multicolumn{2}{|c|}{1995} \\
\hline Test & $\chi^{2}$ & $P$-value & $\chi^{2}$ & $P$-value & $\chi^{2}$ & $P$-value & $\chi^{2}$ & $P$-value \\
\hline 1.Hypothesis ${ }^{1)}-\chi^{2}(1)$ & 2.15 & 0.1427 & 0.01 & 0.9301 & 0.05 & 0.8266 & 1.31 & 0.2527 \\
\hline 2.Hypothesis ${ }^{2)}-\chi^{2}(2)$ & 12.33 & 0.0021 & 2.15 & 0.3415 & 8.06 & 0.0178 & 4.49 & 0.1059 \\
\hline 3.Hypothesis ${ }^{3)}-\chi^{2}(5)$ & 31.64 & 0.0000 & 14.98 & 0.0105 & 23.58 & 0.0003 & 31.71 & 0.0000 \\
\hline 4.Hypothesis ${ }^{4)}-\chi^{2}(6)$ & 34.74 & 0.0000 & 27.95 & 0.0001 & 24.66 & 0.0004 & 33.35 & 0.0000 \\
\hline 5.Hypothesis ${ }^{5)}-\chi^{2}(4)$ & 43.48 & 0.0000 & 57.76 & 0.0000 & 23.37 & 0.0001 & 39.64 & 0.0000 \\
\hline 6.Hypothesis ${ }^{6}-\chi^{2}(10)$ & n.a. & n.a. & 44.49 & 0.0000 & 46.70 & 0.0000 & 47.16 & 0.0082 \\
\hline Durbin's h & 0.25 & 0.4110 & 0.38 & 0.3610 & 0.76 & 0.2240 & 1.16 & 0.1230 \\
\hline
\end{tabular}

Slovak Republic - Total Outflows

\begin{tabular}{|c|c|c|c|c|c|c|c|c|}
\hline \multirow{2}{*}{$\frac{\text { Year }}{\text { Test }}$} & \multicolumn{2}{|c|}{1992} & \multicolumn{2}{|c|}{1993} & \multicolumn{2}{|c|}{1994} & \multicolumn{2}{|c|}{1995} \\
\hline & $\chi^{2}$ & $P$-value & $\chi^{2}$ & $P$-value & $\chi^{2}$ & $P$-value & $\chi^{2}$ & $P$-value \\
\hline 1.Hypothesis ${ }^{1)}-\chi^{2}(1)$ & 0.00 & 0.9999 & 2.72 & 0.6020 & 1.99 & 0.1580 & 1.30 & 0.2540 \\
\hline 2.Hypothesis ${ }^{2)}-\chi^{2}(2)$ & 2.10 & 0.3490 & 17.43 & 0.0000 & 11.57 & 0.0030 & 12.29 & 0.0020 \\
\hline 3.Hypothesis ${ }^{3)}-\chi^{2}(5)$ & 14.60 & 0.0120 & 35.30 & 0.0000 & 26.07 & 0.0000 & 25.34 & 0.0000 \\
\hline 4.Hypothesis ${ }^{4)}-\chi^{2}(6)$ & 15.00 & 0.0200 & 36.40 & 0.0000 & 28.33 & 0.0000 & 29.16 & 0.0000 \\
\hline 5.Hypothesis ${ }^{5)}-\chi^{2}(4)$ & 13.90 & 0.0070 & 33.23 & 0.0000 & 25.26 & 0.0000 & 27.08 & 0.0000 \\
\hline 6.Hypothesis ${ }^{6}-\chi^{2}(10)$ & n.a. & n.a. & 31.66 & 0.0009 & 27.89 & 0.0034 & 39.16 & 0.0000 \\
\hline Durbin's h & 0.35 & 0.3640 & 0.44 & 0.3300 & 1.00 & 0.2590 & 0.93 & 0.1770 \\
\hline
\end{tabular}

1) Weak separability of unemployment and inflow into unemployment

2) Strong separability of unemployment and inflow into unemployment

3) Cobb-Douglas specification

4) Cobb-Douglas specification with constant returns to scale

5) Translog specification with constant returns to scale

6) Stability of coefficients between neighboring years

7) Test of autocorrelation 
Table 2: Estimated Elasticities and Returns to Scale of the Weakly Separable Translog Matching Functions

Czech Republic - Outflows to Jobs

\begin{tabular}{|c|c|c|c|c|}
\hline Year & 1992 & 1993 & 1994 & 1995 \\
\hline Elasticity & $\begin{array}{l}\text { Estimate } \\
\text { (Std.Error) }\end{array}$ & $\begin{array}{l}\text { Estimate } \\
\text { (Std.Error) }\end{array}$ & $\begin{array}{l}\text { Estimate } \\
\text { (Std.Error) }\end{array}$ & $\begin{array}{l}\text { Estimate } \\
\text { (Std.Error) }\end{array}$ \\
\hline$\eta_{U}$ & $\begin{array}{c}1.659 \\
(0.191)\end{array}$ & $\begin{array}{c}1.309 \\
(0.156)\end{array}$ & $\begin{array}{c}1.620 \\
(0.165)\end{array}$ & $\begin{array}{c}1.928 \\
(0.145)\end{array}$ \\
\hline$\eta_{\mathrm{s}}$ & $\begin{array}{c}0.886 \\
(0.136)\end{array}$ & $\begin{array}{c}0.756 \\
(0.106)\end{array}$ & $\begin{array}{c}0.535 \\
(0.090)\end{array}$ & $\begin{array}{c}0.769 \\
(0.092)\end{array}$ \\
\hline$\eta_{v}$ & $\begin{array}{c}0.912 \\
(0.176)\end{array}$ & $\begin{array}{c}1.189 \\
(0.107)\end{array}$ & $\begin{array}{c}0.776 \\
(0.108)\end{array}$ & $\begin{array}{c}0.679 \\
(0.114)\end{array}$ \\
\hline RTS & $\begin{array}{c}3.457 \\
(0.353)\end{array}$ & $\begin{array}{c}3.255 \\
(0.276)\end{array}$ & $\begin{array}{c}2.930 \\
(0.271)\end{array}$ & $\begin{array}{c}3.376 \\
(0.220)\end{array}$ \\
\hline $\begin{array}{c}\operatorname{Test}^{1)}: \chi^{2}(2) \\
(p \text {-value })\end{array}$ & $\begin{array}{l}\text { n.a. } \\
\text { n.a. }\end{array}$ & $\begin{array}{c}0.205 \\
(0.900)\end{array}$ & $\begin{array}{c}0.701 \\
(0.650)\end{array}$ & $\begin{array}{c}1.629 \\
(0.450)\end{array}$ \\
\hline
\end{tabular}

Czech Republic - Total Outflows

\begin{tabular}{|c|c|c|c|c|}
\hline Year & $\mathbf{1 9 9 2}$ & $\mathbf{1 9 9 3}$ & $\mathbf{1 9 9 4}$ & $\mathbf{1 9 9 5}$ \\
\hline \multirow{3}{*}{ Elasticity } & $\begin{array}{c}\text { Estimate } \\
(\text { Std.Error })\end{array}$ & $\begin{array}{c}\text { Estimate } \\
(\text { Std.Error })\end{array}$ & $\begin{array}{c}\text { Estimate } \\
(\text { Std.Error })\end{array}$ & $\begin{array}{c}\text { Estimate } \\
(\text { Std.Error })\end{array}$ \\
\hline$\eta_{\mathbf{U}}$ & 1.226 & 0.973 & 1.505 & 1.755 \\
& $(0.150)$ & $(0.135)$ & $(0.153)$ & $(0.125)$ \\
$\eta_{\mathbf{S}}$ & 0.745 & 0.569 & 0.425 & 0.754 \\
& $(0.114)$ & $(0.085)$ & $(0.084)$ & $(0.081)$ \\
$\eta_{\mathbf{v}}$ & 0.651 & 0.997 & 0.833 & 0.669 \\
& $(0.139)$ & $(0.092)$ & $(0.102)$ & $(0.106)$ \\
RTS & 2.623 & 2.539 & 2.763 & 2.177 \\
& $(0.275)$ & $(0.237)$ & $(0.253)$ & $(0.195)$ \\
Test ${ }^{\mathbf{1}}: \chi^{\mathbf{2}} \mathbf{( 2 )}$ & n.a. & 0.054 & 0.420 & 3.376 \\
$(p$-value $)$ & n.a. & $(0.900)$ & $(0.720)$ & $(0.180)$ \\
\hline
\end{tabular}


Slovak Republic - Total Outflows

\begin{tabular}{|c|c|c|c|c|}
\hline Year & $\mathbf{1 9 9 2}$ & $\mathbf{1 9 9 3}$ & $\mathbf{1 9 9 4}$ & $\mathbf{1 9 9 5}$ \\
\hline \multirow{3}{*}{ Elasticity } & $\begin{array}{c}\text { Estimate } \\
(\text { Std.Error })\end{array}$ & $\begin{array}{c}\text { Estimate } \\
(\text { Std.Error })\end{array}$ & $\begin{array}{c}\text { Estimate } \\
(\text { Std.Error })\end{array}$ & $\begin{array}{c}\text { Estimate } \\
(\text { Std.Error })\end{array}$ \\
\hline$\eta_{\mathbf{U}}$ & 0.088 & -0.370 & 1.343 & 0.919 \\
& $(0.297)$ & $(0.562)$ & $(0.582)$ & $(0.300)$ \\
$\eta_{\mathbf{S}}$ & -0.028 & 0.040 & -0.037 & -0.080 \\
& $(0.111)$ & $(0.119)$ & $(0.115)$ & $(0.104)$ \\
$\eta_{\mathbf{v}}$ & 0.136 & 0.223 & 0.076 & 0.044 \\
& $(0.087)$ & $(0.087)$ & $(0.088)$ & $(0.077)$ \\
RTS & 0.200 & 0.100 & 1.382 & 0.890 \\
& $(0.398)$ & $(0.086)$ & $(0.665)$ & $(0.403)$ \\
Test ${ }^{\mathbf{1}}: \chi^{\mathbf{2}}(\mathbf{2})$ & n.a. & 0.060 & 3.655 & 0.400 \\
$(p$-value $)$ & $n . a$. & $(0.880)$ & $(0.170)$ & $(0.710)$ \\
\hline
\end{tabular}

$\eta_{\mathrm{U}} \quad$ elasticity of the outflow with respect to the unemployment

$\eta_{\mathrm{s}}$ elasticity of the outflow with respect to the inflow into unemployment

$\eta_{\mathrm{v}} \quad$ elasticity of the outflow with respect to the vacancies

RTS returns to scale

Note: The elasticities and returns to scale are evaluated at the geometric means of the relevant variables.

1) Test of stability of RTS between neighboring years 
Table 3: Second Stage AHIV Estimates of the Effects of Structural and Policy Variables on Matching

Czech Republic

Slovak Republic

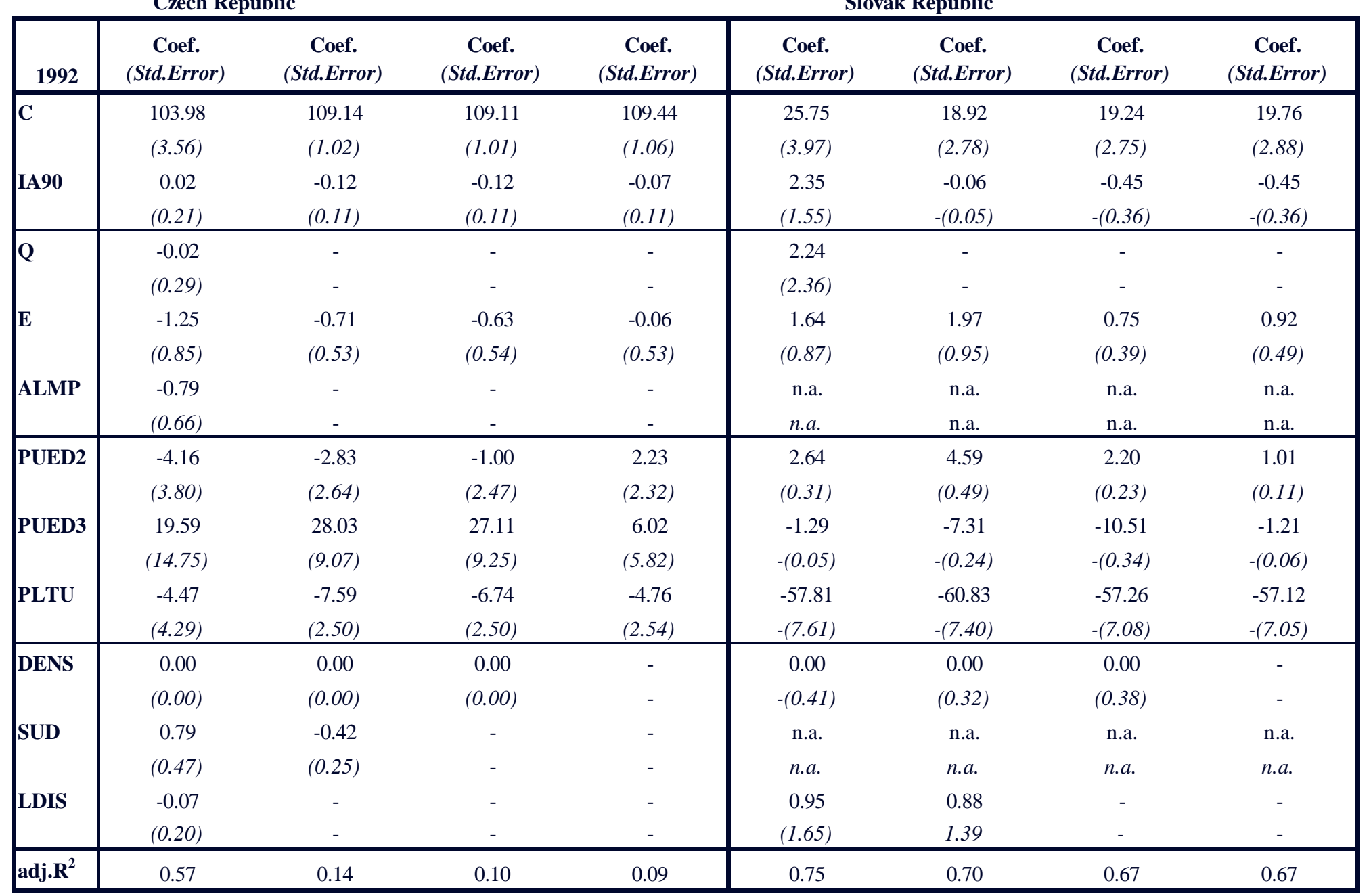


Table 3: continued

Czech Republic

Slovak Republic

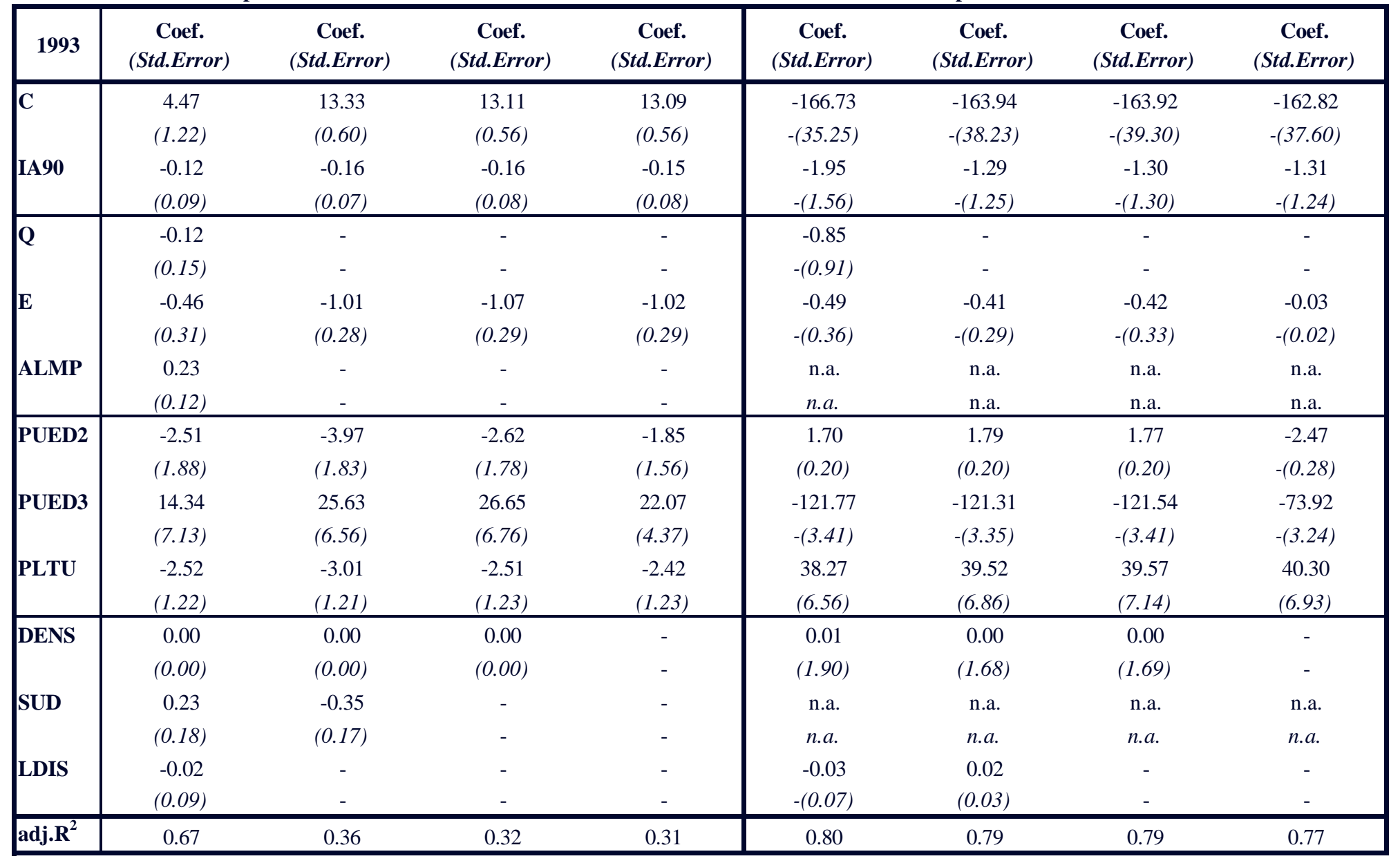


Table 3: continued

Czech Republic

Slovak Republic

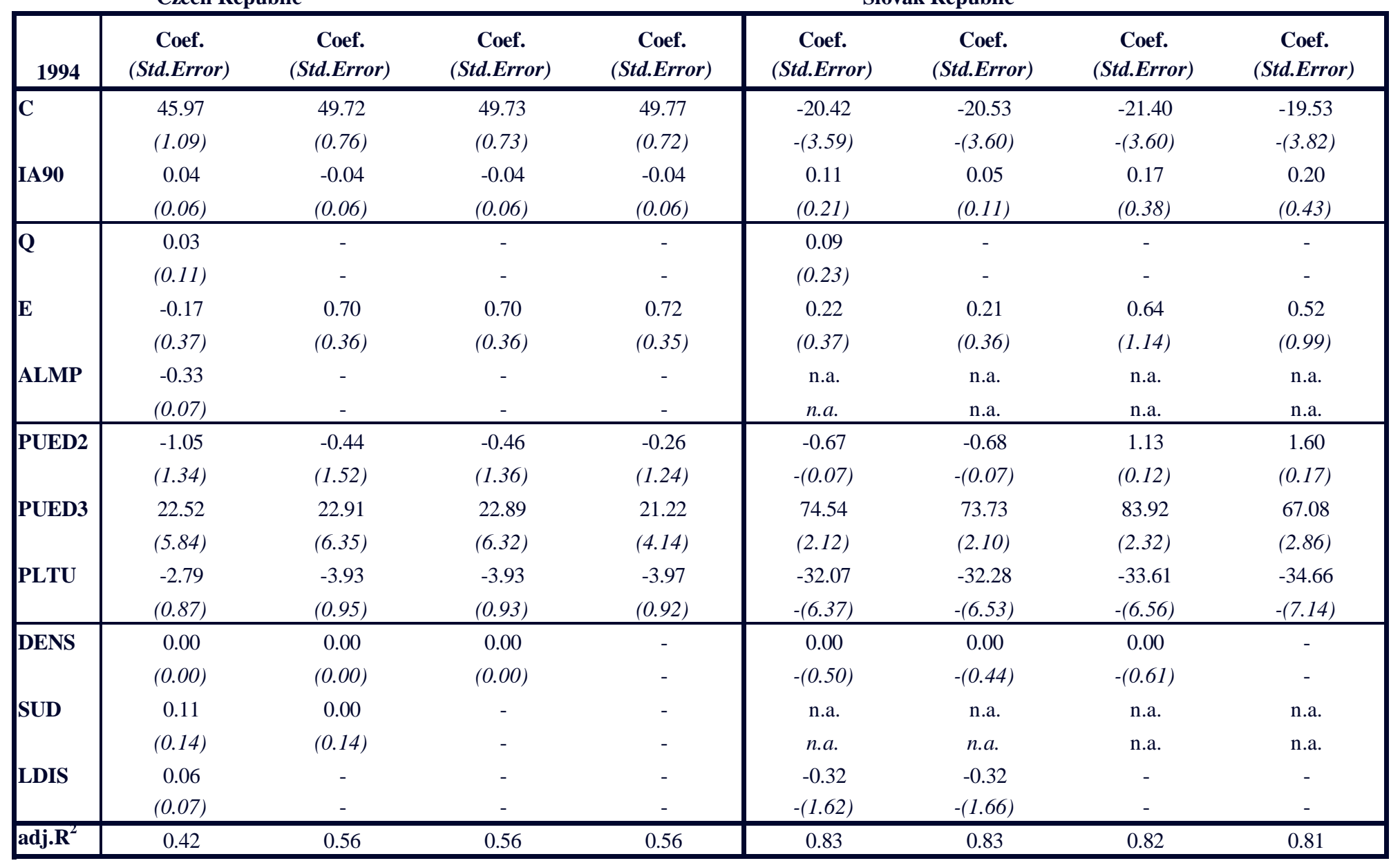


Table 3: continued

Czech Republic

Slovak Republic

\begin{tabular}{|c|c|c|c|c|c|c|c|c|}
\hline 1995 & $\begin{array}{c}\text { Coef. } \\
\text { (Std.Error) }\end{array}$ & $\begin{array}{c}\text { Coef. } \\
\text { (Std.Error) }\end{array}$ & $\begin{array}{c}\text { Coef. } \\
\text { (Std.Error) }\end{array}$ & $\begin{array}{c}\text { Coef. } \\
\text { (Std.Error) }\end{array}$ & $\begin{array}{c}\text { Coef. } \\
\text { (Std.Error) }\end{array}$ & $\begin{array}{c}\text { Coef. } \\
\text { (Std.Error) }\end{array}$ & $\begin{array}{c}\text { Coef. } \\
\text { (Std.Error) }\end{array}$ & $\begin{array}{c}\text { Coef. } \\
\text { (Std.Error) }\end{array}$ \\
\hline $\mathrm{C}$ & 30.35 & 31.52 & 31.50 & 31.73 & -13.48 & -21.99 & -24.50 & -25.18 \\
\hline \multirow[t]{2}{*}{ IA90 } & 0.01 & -0.10 & -0.10 & -0.10 & -0.77 & -0.62 & -0.49 & -0.36 \\
\hline & $(0.07)$ & $(0.07)$ & $(0.07)$ & $(0.08)$ & $-(0.63)$ & $-(0.53)$ & $-(0.42)$ & $-(0.29)$ \\
\hline $\mathbf{Q}$ & 0.07 & - & - & - & 0.68 & - & - & - \\
\hline \multirow[t]{2}{*}{$\mathbf{E}$} & 0.25 & 1.18 & 1.19 & 1.37 & 0.20 & 0.24 & 0.34 & 0.18 \\
\hline & $(0.37)$ & $(0.38)$ & $(0.38)$ & $(0.38)$ & $(0.82)$ & $(1.00)$ & $(1.70)$ & $(0.95)$ \\
\hline \multirow[t]{2}{*}{ ALMP } & -0.38 & - & - & - & n.a. & - & - & - \\
\hline & $(0.07)$ & - & - & - & n.a. & - & - & - \\
\hline PUED2 & -3.17 & -0.58 & -0.14 & 1.47 & 9.93 & 9.25 & 12.48 & 11.20 \\
\hline \multirow[t]{2}{*}{ PLTU } & -3.40 & -4.62 & -4.54 & -4.77 & 11.86 & 12.03 & 12.07 & 14.12 \\
\hline & $(0.80)$ & $(1.02)$ & $(1.01)$ & $(1.04)$ & $(2.57)$ & $(2.60)$ & $(2.59)$ & $(2.97)$ \\
\hline \multirow[t]{2}{*}{ DENS } & 0.00 & 0.00 & 0.00 & - & 0.00 & 0.00 & -0.01 & - \\
\hline & $(0.00)$ & $(0.00)$ & $(0.00)$ & - & $-(1.35)$ & $-(1.37)$ & $-(1.73)$ & - \\
\hline \multirow[t]{2}{*}{ SUD } & 0.36 & -0.10 & - & - & n.a. & n.a. & n.a. & - \\
\hline & $(0.15)$ & $(0.17)$ & - & - & n.a. & n.a. & n.a. & - \\
\hline \multirow[t]{2}{*}{ LDIS } & 0.04 & - & - & - & -0.56 & - & - & - \\
\hline & $(0.08)$ & - & - & - & $-(0.89)$ & - & - & - \\
\hline $\operatorname{adj} . R^{2}$ & 0.77 & 0.61 & 0.61 & 0.58 & 0.64 & 0.64 & 0.63 & 0.59 \\
\hline
\end{tabular}


Table A1: Summary Statistics

Czech Republic

\begin{tabular}{|c|l|r|r|r|r|}
\hline Year & \multicolumn{1}{|c|}{ Variable } & Mean $^{\text {a) }}$ & Std. Dev. & Mean $^{\text {b) }}$ & Std. Dev. D $^{\text {b }}$ \\
\hline 1991 & Inflow & 520.2 & 224.8 & 506.2 & 413.7 \\
& Outflow & 203.6 & 151.3 & 201.1 & 228.8 \\
& Unemployment & 1988.2 & 1136.0 & 1945.2 & 1759.6 \\
& Vacancies & 462.9 & 291.1 & 543.4 & 1046.8 \\
\hline 1992 & Inflow & 460.8 & 199.6 & 425.2 & 314.4 \\
& Outflow & 397.0 & 204.5 & 362.9 & 279.0 \\
& Unemployment & 2340.6 & 1158.2 & 2100.4 & 1506.2 \\
& Vacancies & 944.7 & 510.8 & 993.3 & 1894.1 \\
\hline 1993 & Inflow & 513.6 & 235.1 & 471.3 & 353.7 \\
& Outflow & 343.4 & 161.7 & 308.2 & 211.2 \\
& Unemployment & 2292.4 & 1157.7 & 2069.9 & 1590.5 \\
& Vacancies & 866.5 & 460.1 & 898.6 & 1920.8 \\
\hline 1994 & Inflow & 454.6 & 207.9 & 424.3 & 306.5 \\
& Outflow & 362.5 & 182.9 & 329.8 & 228.2 \\
& Unemployment & 2424.5 & 1283.8 & 2253.7 & 1815.7 \\
& Vacancies & 946.4 & 401.9 & 974.6 & 1704.4 \\
\hline 1995 & Inflow & 409.9 & 202.4 & 386.2 & 286.7 \\
& Outflow & 313.0 & 166.2 & 288.9 & 210.9 \\
& Unemployment & 2175.5 & 1198.2 & 2039.6 & 1660.3 \\
& Vacancies & 1213.7 & 443.9 & 1200.6 & 1598.6 \\
\hline 1996 & Inflow & 431.9 & 216.7 & 406.1 & 305.4 \\
& Outflow & 306.5 & 153.3 & 280.2 & 189.7 \\
& Unemployment & 2200.4 & 1214.5 & 2046.5 & 1610.5 \\
& Vacancies & 1380.0 & 519.8 & 1335.4 & 1651.4 \\
\hline
\end{tabular}

Slovak Republic

\begin{tabular}{|c|l|r|r|r|r|}
\hline Year & \multicolumn{1}{|c|}{ Variable } & Mean $^{\text {a) }}$ & Std. Dev. & Mean $^{\text {a) }}$ & Std. Dev. D $^{\text {b) }}$ \\
\hline 1991 & Inflow & 881.5 & 367.2 & 814.1 & 464.4 \\
& Outflow & 247.2 & 208.9 & 231.5 & 222.2 \\
& Unemployment & 5122.9 & 2756.3 & 4736.6 & 3210.1 \\
& Vacancies & 193.4 & 164.1 & 197.4 & 258.3 \\
\hline 1992 & Inflow & 727.5 & 282.7 & 663.4 & 341.2 \\
& Outflow & 794.5 & 328.2 & 754.8 & 516.1 \\
& Unemployment & 8290.0 & 2353.4 & 7467.8 & 3040.0 \\
& Vacancies & 313.9 & 245.6 & 358.8 & 604.8 \\
\hline 1993 & Inflow & 1004.9 & 353.9 & 906.6 & 416.1 \\
& Outflow & 730.5 & 260.6 & 670.1 & 329.7 \\
& Unemployment & 9805.4 & 2942.8 & 8623.9 & 3058.7 \\
& Vacancies & 259.2 & 182.1 & 277.9 & 357.8 \\
\hline 1994 & Inflow & 763.9 & 257.4 & 717.8 & 313.1 \\
& Outflow & 743.1 & 223.5 & 710.4 & 327.9 \\
& Unemployment & 10606.8 & 3151.8 & 9639.7 & 3194.3 \\
& Vacancies & 275.0 & 202.1 & 291.5 & 319.5 \\
\hline 1995 & Inflow & 843.1 & 298.1 & 783.2 & 344.8 \\
& Outflow & 935.6 & 331.4 & 867.0 & 369.9 \\
& Unemployment & 10108.9 & 3295.6 & 9163.9 & 3294.1 \\
& Vacancies & 414.0 & 337.1 & 409.5 & 408.5 \\
\hline 1996 & Inflow & 922.3 & 373.6 & 839.1 & 366.6 \\
& Outflow & 906.5 & 373.0 & 834.4 & 381.1 \\
& Unemployment & 9595.4 & 3312.9 & 8567.3 & 3028.9 \\
& Vacancies & 450.1 & 306.1 & 453.9 & 458.6 \\
\hline
\end{tabular}

a) Data adjusted for district size

b) Unadjusted data 
Table A2: Correlation Coefficients for the Czech Republic

Variables Unadjusted for District Size

\begin{tabular}{|c|l|r|r|r|}
\hline Year & Variable & \multicolumn{1}{c|}{ Inflow } & \multicolumn{1}{c|}{ Outflow } & Unempl. \\
\hline $\mathbf{1 9 9 1}$ & Outflow & 0.83 & & \\
& Unemployment & 0.87 & 0.81 & \\
& Vacancies & 0.70 & 0.68 & 0.61 \\
\hline $\mathbf{1 9 9 2}$ & Outflow & 0.79 & & \\
& Unemployment & 0.82 & 0.77 & \\
& Vacancies & 0.34 & 0.37 & 0.14 \\
\hline $\mathbf{1 9 9 3}$ & Outflow & 0.83 & & \\
& Unemployment & 0.86 & 0.78 & \\
& Vacancies & 0.25 & 0.29 & 0.03 \\
\hline $\mathbf{1 9 9 4}$ & Outflow & 0.86 & & \\
& Unemployment & 0.90 & 0.85 & \\
& Vacancies & 0.25 & 0.19 & 0.03 \\
\hline $\mathbf{1 9 9 5}$ & Outflow & 0.85 & & \\
& Unemployment & 0.89 & 0.84 & \\
& Vacancies & 0.29 & 0.19 & 0.11 \\
\hline $\mathbf{1 9 9 6}$ & Outflow & 0.84 & & \\
& Unemployment & 0.88 & 0.85 & \\
& Vacancies & 0.28 & 0.22 & 0.12 \\
\hline
\end{tabular}

Variables Adjusted for District Size

\begin{tabular}{|c|l|r|r|r|}
\hline Year & Variable & \multicolumn{1}{|c|}{ Inflow } & Outflow & Unempl. \\
\hline $\mathbf{1 9 9 1}$ & Outflow & 0.65 & & \\
& Unemployment & 0.71 & 0.66 & \\
& Vacancies & -0.09 & 0.03 & -0.18 \\
\hline $\mathbf{1 9 9 2}$ & Outflow & 0.54 & & \\
& Unemployment & 0.64 & 0.60 & \\
& Vacancies & -0.30 & -0.29 & -0.52 \\
\hline $\mathbf{1 9 9 3}$ & Outflow & 0.66 & & \\
& Unemployment & 0.80 & 0.70 & \\
& Vacancies & -0.46 & -0.40 & -0.58 \\
\hline $\mathbf{1 9 9 4}$ & Outflow & 0.70 & & \\
& Unemployment & 0.84 & 0.74 & \\
& Vacancies & -0.42 & -0.37 & -0.50 \\
\hline $\mathbf{1 9 9 5}$ & Outflow & 0.71 & & \\
& Unemployment & 0.83 & 0.73 & \\
& Vacancies & -0.27 & -0.22 & -0.29 \\
\hline $\mathbf{1 9 9 6}$ & Outflow & 0.68 & & \\
& Unemployment & 0.82 & 0.74 & \\
& Vacancies & -0.20 & -0.19 & -0.21 \\
\hline
\end{tabular}


Table A3: Correlation Coefficients for the Slovak Republic

Variables Unadjusted for District Size

\begin{tabular}{|c|l|r|r|r|}
\hline Year & Variable & \multicolumn{1}{|c|}{ Inflow } & \multicolumn{1}{c|}{ Outflow } & Unempl. \\
\hline $\mathbf{1 9 9 1}$ & Outflow & 0.59 & & \\
& Unemployment & 0.76 & 0.74 & \\
& Vacancies & 0.42 & 0.44 & 0.41 \\
\hline $\mathbf{1 9 9 2}$ & Outflow & 0.56 & & \\
& Unemployment & 0.68 & 0.57 & \\
& Vacancies & 0.52 & 0.59 & 0.49 \\
\hline $\mathbf{1 9 9 3}$ & Outflow & 0.66 & & \\
& Unemployment & 0.63 & 0.60 & \\
& Vacancies & 0.52 & 0.58 & 0.36 \\
\hline $\mathbf{1 9 9 4}$ & Outflow & 0.67 & & \\
& Unemployment & 0.65 & 0.57 & \\
& Vacancies & 0.53 & 0.61 & 0.30 \\
\hline $\mathbf{1 9 9 5}$ & Outflow & 0.56 & & \\
& Unemployment & 0.60 & 0.57 & \\
& Vacancies & 0.47 & 0.40 & 0.14 \\
\hline $\mathbf{1 9 9 6}$ & Outflow & 0.46 & & \\
& Unemployment & 0.60 & 0.54 & \\
& Vacancies & 0.31 & 0.39 & 0.08 \\
\hline
\end{tabular}

Variables Adjusted for District Size

\begin{tabular}{|c|l|r|r|r|}
\hline Year & \multicolumn{1}{|c|}{ Variable } & \multicolumn{1}{c|}{ Inflow } & \multicolumn{1}{c|}{ Outflow } & Unempl. \\
\hline $\mathbf{1 9 9 1}$ & Outflow & 0.41 & & \\
& Unemployment & 0.63 & 0.63 & \\
& Vacancies & -0.11 & 0.01 & -0.09 \\
\hline $\mathbf{1 9 9 2}$ & Outflow & 0.22 & & \\
& Unemployment & 0.42 & 0.19 & \\
& Vacancies & 0.00 & 0.16 & -0.18 \\
\hline $\mathbf{1 9 9 3}$ & Outflow & 0.35 & & \\
& Unemployment & 0.41 & 0.25 & \\
& Vacancies & 0.07 & 0.11 & -0.16 \\
\hline $\mathbf{1 9 9 4}$ & Outflow & 0.20 & & \\
& Unemployment & 0.42 & 0.24 & \\
& Vacancies & 0.00 & 0.05 & -0.26 \\
\hline $\mathbf{1 9 9 5}$ & Outflow & 0.21 & & \\
& Unemployment & 0.45 & 0.41 & \\
& Vacancies & 0.04 & -0.03 & -0.28 \\
\hline $\mathbf{1 9 9 6}$ & Outflow & 0.19 & & \\
& Unemployment & 0.53 & 0.41 & \\
& Vacancies & -0.10 & -0.01 & -0.31 \\
\hline
\end{tabular}


Table A4: Estimated Coefficients of Unconstrained Translog Matching Function (1)

and with Weak Separability Between the Existing and Newly Unemployed Individuals (2)

\begin{tabular}{|c|c|c|c|c|c|c|c|c|c|c|c|c|c|c|c|c|}
\hline \multirow{3}{*}{\begin{tabular}{|c|} 
Year \\
Model \\
Variable \\
\end{tabular}} & \multicolumn{4}{|c|}{1992} & \multicolumn{4}{|c|}{1993} & \multicolumn{4}{|c|}{1994} & \multicolumn{4}{|c|}{1995} \\
\hline & \multicolumn{2}{|c|}{ (1) } & \multirow{2}{*}{\multicolumn{2}{|c|}{$\frac{\text { (2) }}{\text { Estimate } \text { Std.Error }}$}} & \multirow{2}{*}{\multicolumn{2}{|c|}{\begin{tabular}{|c|} 
(1) \\
Estimate Std.Error
\end{tabular}}} & \multirow{2}{*}{\multicolumn{2}{|c|}{ (2) }} & \multirow{2}{*}{\multicolumn{2}{|c|}{$\frac{\text { (1) }}{\text { (1) }}$}} & \multicolumn{2}{|c|}{ (2) } & \multicolumn{2}{|c|}{ (1) } & \multicolumn{2}{|c|}{ (2) } \\
\hline & Estimate & Std.Error & & & & & & 1.Error & & & Estimate & d.Error & Estimate & l. Error & Estimate & l.Error \\
\hline Trend & 0.061 & 0.024 & 0.057 & 0.023 & 0.052 & 0.022 & 0.056 & 0.020 & 0.117 & 0.031 & $\begin{array}{l}0.107 \\
\end{array}$ & 0.029 & \begin{tabular}{|l|l|}
0.108 \\
\end{tabular} & 0.044 & \begin{tabular}{|l|}
0.074 \\
\end{tabular} & 0.037 \\
\hline$\gamma_{0}$ & 0.319 & 0.052 & 0.320 & 0.051 & 0.297 & 0.056 & 0.303 & 0.053 & 0.267 & 0.045 & 0.244 & 0.041 & 0.410 & 0.050 & 0.345 & 0.040 \\
\hline$\beta_{u}$ & -10.004 & 4.474 & 0.588 & 0.904 & 11.350 & 2.862 & 3.430 & 2.156 & 8.259 & 2.967 & 7.110 & 2.852 & 10.035 & 3.159 & 8.850 & 2.780 \\
\hline$\beta_{s}$ & 18.851 & 6.655 & 22.376 & 5.955 & -6.087 & 3.909 & 1.057 & 3.031 & 8.056 & 6.495 & 1.993 & 2.289 & 9.931 & 4.271 & -1.452 & 1.132 \\
\hline$\beta_{v}$ & -2.783 & 4.288 & 6.515 & 1.729 & 3.775 & 3.697 & -0.198 & 3.392 & 12.325 & 3.466 & 11.444 & 3.272 & 4.246 & 3.092 & 7.202 & 2.590 \\
\hline$\gamma_{U S}$ & 0.041 & 0.009 & 0.041 & 0.009 & 0.031 & 0.008 & 0.035 & 0.008 & 0.026 & 0.009 & 0.022 & 0.008 & 0.026 & 0.010 & 0.016 & 0.009 \\
\hline$\gamma_{U V}$ & -1.248 & 0.512 & 0.011 & 0.017 & 1.031 & 0.367 & 0.067 & 0.276 & 0.854 & 0.320 & 0.795 & 0.315 & 0.109 & 0.378 & 0.484 & 0.316 \\
\hline$\gamma_{\mathrm{sv}}$ & 0.301 & 0.230 & 0.411 & 0.206 & -0.424 & 0.254 & 0.021 & 0.101 & 0.317 & 0.305 & 0.222 & 0.259 & -0.128 & 0.076 & -0.079 & 0.066 \\
\hline$\gamma_{U u}$ & -1.732 & 0.623 & -0.407 & 0.250 & 1.349 & 0.363 & 0.428 & 0.294 & 0.754 & 0.476 & 0.523 & 0.448 & 2.005 & 0.582 & 1.328 & 0.469 \\
\hline$\gamma_{\mathrm{ss}}$ & 2.047 & 0.719 & 2.424 & 0.651 & -0.623 & 0.389 & 0.010 & 0.338 & 0.740 & 0.679 & 0.051 & 0.147 & 1.171 & 0.521 & -0.241 & 0.110 \\
\hline$\gamma_{\mathrm{w} v}$ & -0.362 & 0.384 & 0.504 & 0.223 & 0.483 & 0.482 & -0.394 & 0.417 & 1.367 & 0.399 & 1.388 & 0.392 & 1.008 & 0.616 & 1.321 & 0.539 \\
\hline adj. $R^{2}$ & 0.172 & & 0.184 & & 0.148 & & 0.152 & & 0.150 & & 0.166 & & 0.200 & & 0.260 & \\
\hline Nobs & 912 & & 912 & & 912 & & 912 & & 912 & & 912 & & 912 & & 912 & \\
\hline
\end{tabular}

Slovak Republic - Total Outflows

\begin{tabular}{|c|c|c|c|c|c|c|c|c|c|c|c|c|c|c|c|c|}
\hline Year & \multicolumn{4}{|c|}{1992} & \multicolumn{4}{|c|}{1993} & \multicolumn{4}{|c|}{1994} & \multicolumn{4}{|c|}{1995} \\
\hline Model & \multicolumn{2}{|c|}{ (1) } & \multirow{2}{*}{\multicolumn{2}{|c|}{$\frac{\text { (2) }}{\text { Estimate Std.Error }}$}} & \multirow{2}{*}{\multicolumn{2}{|c|}{\begin{tabular}{|c|} 
(1) \\
Estimate Std.Error
\end{tabular}}} & \multirow{2}{*}{\multicolumn{2}{|c|}{$\frac{\text { (2) }}{\text { Fstim }}$}} & \multicolumn{2}{|c|}{ (1) } & \multicolumn{2}{|c|}{ (2) } & \multirow{2}{*}{\multicolumn{2}{|c|}{$\begin{array}{c}\text { (1) } \\
\end{array}$}} & \multicolumn{2}{|c|}{ (2) } \\
\hline Variable & Estimate & Std.Error & & & & & & & Estimate & Std.Error & Estimate $S$ & Std.Error & & & Estimate & Std.Errol \\
\hline Trend & 0.072 & 0.062 & 0.071 & 0.057 & -0.211 & 0.076 & $\begin{array}{l}-0.149 \\
\end{array}$ & 0.062 & -0.129 & 0.040 & -0.136 & 0.038 & -0.044 & 0.028 & -0.038 & 0.025 \\
\hline$\gamma_{0}$ & 0.400 & 0.052 & 0.400 & 0.050 & 0.205 & 0.066 & 0.188 & 0.063 & 0.417 & 0.065 & 0.398 & 0.062 & 0.513 & 0.056 & 0.490 & 0.050 \\
\hline$\beta_{u}$ & 1.405 & 6.384 & 1.100 & 2.093 & -4.926 & 6.921 & -4.588 & 6.640 & -15.091 & 7.809 & -11.806 & 7.179 & -6.115 & 4.397 & 0.072 & 3.342 \\
\hline$\beta_{\mathrm{s}}$ & -10.355 & 3.982 & -10.391 & 3.908 & -20.285 & 4.310 & -22.034 & 3.990 & -13.704 & 3.206 & -12.827 & 3.030 & -12.379 & 3.025 & -13.636 & 2.730 \\
\hline$\beta_{v}$ & 1.754 & 2.121 & 1.670 & 1.319 & -10.407 & 2.704 & -8.527 & 2.314 & -6.220 & 1.845 & -5.541 & 1.716 & -6.892 & 2.219 & -2.618 & 1.317 \\
\hline$\gamma_{u s}$ & -0.011 & 0.012 & -0.011 & 0.011 & 0.024 & 0.014 & 0.011 & 0.011 & 0.014 & 0.720 & 0.016 & 0.007 & 0.003 & 0.556 & 0.003 & 0.005 \\
\hline$\gamma_{u v}$ & 0.000 & 0.496 & -0.025 & 0.052 & -0.632 & 0.408 & -0.199 & 0.284 & -0.782 & 0.367 & -0.400 & 0.237 & -0.918 & 0.377 & 0.002 & 0.091 \\
\hline$\gamma_{\mathrm{sv}}$ & 0.234 & 0.162 & 0.233 & 0.160 & -0.959 & 0.243 & -0.956 & 0.233 & -0.343 & 0.160 & -0.435 & 0.140 & -0.460 & 0.172 & -0.370 & 0.154 \\
\hline$\gamma_{U U}$ & 0.656 & 1.938 & 0.576 & 1.120 & -0.779 & 2.440 & -1.577 & 2.288 & -6.631 & 3.424 & -5.861 & 3.257 & -1.352 & 1.676 & -0.456 & 1.499 \\
\hline$\gamma_{s s}$ & -1.491 & 0.474 & -1.495 & 0.467 & -1.950 & 0.507 & -2.172 & 0.466 & -1.520 & 0.419 & -1.334 & 0.383 & -1.286 & 0.387 & -1.505 & 0.345 \\
\hline$\gamma_{\mathrm{w}}$ & -0.037 & 0.133 & -0.041 & 0.101 & -0.358 & 0.179 & -0.183 & 0.133 & -0.381 & 0.161 & -0.262 & 0.132 & -0.307 & 0.173 & 0.034 & 0.099 \\
\hline adj. $R^{2}$ & 0.175 & & 0.178 & & 0.034 & & 0.013 & & 0.071 & & 0.062 & & 0.200 & & 0.274 & \\
\hline Nobs & 456 & & 456 & & 456 & & 456 & & 456 & & 456 & & 456 & & 456 & \\
\hline
\end{tabular}

Czech Republic - Total Outflows

\begin{tabular}{|c|c|c|c|c|c|c|c|c|c|c|c|c|c|c|c|c|}
\hline \multirow{3}{*}{$\begin{array}{c}\text { Year } \\
\text { Model } \\
\text { Variable }\end{array}$} & \multicolumn{4}{|c|}{1992} & \multicolumn{4}{|c|}{1993} & \multicolumn{4}{|c|}{1994} & \multicolumn{4}{|c|}{1995} \\
\hline & \multicolumn{2}{|c|}{ (1) } & \multirow{2}{*}{\multicolumn{2}{|c|}{$\frac{\text { (2) }}{\text { Estimate Std.Error }}$}} & \multicolumn{2}{|c|}{ (1) } & \multicolumn{2}{|c|}{ (2) } & \multicolumn{2}{|c|}{ (1) } & \multicolumn{2}{|c|}{ (2) } & \multicolumn{2}{|c|}{ (1) } & \multicolumn{2}{|c|}{ (2) } \\
\hline & Estimate & Std.Error & & id.Error & Estimate & It.Error & Estimate & Id.Error & Estimate & td.Error & Estimate & Std.Error & Estimate & Std.Error & Estimate & Std.Error \\
\hline Trend & 0.062 & 0.019 & 0.058 & 0.018 & 0.039 & 0.017 & 0.041 & 0.017 & \begin{tabular}{|l|}
0.109 \\
\end{tabular} & 0.028 & 0.111 & 0.027 & 0.079 & 0.039 & 0.049 & 0.034 \\
\hline$\gamma_{0}$ & 0.407 & 0.047 & 0.398 & 0.045 & 0.291 & 0.051 & 0.295 & 0.050 & 0.196 & 0.045 & 0.200 & 0.042 & 0.448 & 0.046 & 0.390 & 0.037 \\
\hline$\beta_{u}$ & 4.395 & 3.749 & 0.354 & 0.770 & 5.711 & 2.401 & 4.220 & 2.310 & 5.549 & 2.705 & 5.660 & 2.660 & 9.132 & 2.778 & 8.539 & 2.520 \\
\hline$\beta_{\mathrm{s}}$ & 15.693 & 5.328 & 19.134 & 4.949 & -0.477 & 2.982 & 0.695 & 2.803 & 1.495 & 5.664 & 2.704 & 1.814 & 7.254 & 3.591 & -1.711 & 0.903 \\
\hline$\beta_{\mathrm{v}}$ & -0.449 & 3.516 & 6.389 & 1.352 & 2.388 & 2.968 & 1.874 & 2.965 & 11.634 & 3.201 & 11.891 & 2.993 & 5.059 & 2.582 & 7.015 & 2.253 \\
\hline$\gamma_{u s}$ & 0.032 & 0.007 & 0.030 & 0.007 & 0.023 & 0.007 & 0.024 & 0.006 & 0.022 & 0.008 & 0.023 & 0.007 & 0.017 & 0.009 & 0.008 & 0.008 \\
\hline$\gamma_{u v}$ & -0.904 & 0.432 & 0.009 & 0.020 & 0.445 & 0.308 & 0.285 & 0.300 & 0.700 & 0.289 & 0.704 & 0.289 & 0.224 & 0.330 & 0.539 & 0.280 \\
\hline$\gamma_{\mathrm{sv}}$ & 0.343 & 0.182 & 0.479 & 0.166 & -0.023 & 0.199 & 0.047 & 0.184 & 0.305 & 0.270 & 0.336 & 0.232 & -0.132 & 0.064 & -0.108 & 0.058 \\
\hline 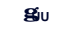 & -1.331 & 0.521 & -0.324 & 0.207 & 0.640 & 0.307 & 0.490 & 0.293 & 0.228 & 0.438 & 0.252 & 0.425 & 1.711 & 0.510 & 1.233 & 0.434 \\
\hline$\gamma_{s s}$ & 1.658 & 0.578 & 2.006 & 0.540 & -0.127 & 0.299 & -0.022 & 0.247 & -0.042 & 0.595 & 0.090 & 0.108 & 0.851 & 0.436 & -0.253 & 0.087 \\
\hline$\gamma_{\mathrm{w}}$ & -0.148 & 0.321 & 0.413 & 0.176 & -0.008 & 0.382 & -0.115 & 0.379 & 1.341 & 0.356 & 1.341 & 0.356 & 1.120 & 0.525 & 1.287 & 0.475 \\
\hline adj. $R^{2}$ & 0.209 & & 0.221 & & 0.161 & & 0.139 & & 0.165 & & 0.165 & & 0.242 & & 0.298 & \\
\hline Nobs & 912 & & 912 & & 912 & & 912 & & 912 & & 912 & & 912 & & 912 & \\
\hline
\end{tabular}


Table A5: Estimated Elasticities and Returns to Scale of the Unconstrained Translog Matching Functions

Czech Republic - Outflows to Jobs

\begin{tabular}{|c|c|c|c|c|}
\hline Year & 1992 & 1993 & 1994 & 1995 \\
\hline Elasticity & $\begin{array}{l}\text { Estimate } \\
\text { (Std.Error) }\end{array}$ & $\begin{array}{l}\text { Estimate } \\
\text { (Std.Error) }\end{array}$ & $\begin{array}{l}\text { Estimate } \\
\text { (Std.Error) }\end{array}$ & $\begin{array}{l}\text { Estimate } \\
\text { (Std.Error) }\end{array}$ \\
\hline$\eta_{u}$ & $\begin{array}{c}1.508 \\
(0.213)\end{array}$ & $\begin{array}{c}1.457 \\
(0.163)\end{array}$ & $\begin{array}{c}1.636 \\
(0.170)\end{array}$ & $\begin{array}{c}2.104 \\
(0.174)\end{array}$ \\
\hline$\eta_{s}$ & $\begin{array}{c}0.791 \\
(0.151)\end{array}$ & $\begin{array}{c}0.728 \\
(0.112)\end{array}$ & $\begin{array}{c}0.602 \\
(0.108)\end{array}$ & $\begin{array}{c}0.872 \\
(0.109)\end{array}$ \\
\hline$\eta_{\mathrm{v}}$ & $\begin{array}{c}0.960 \\
(0.189)\end{array}$ & $\begin{array}{c}1.222 \\
(0.111)\end{array}$ & $\begin{array}{c}0.744 \\
(0.114)\end{array}$ & $\begin{array}{c}0.758 \\
(0.131)\end{array}$ \\
\hline RTS & $\begin{array}{c}3.260 \\
(0.386)\end{array}$ & $\begin{array}{c}3.407 \\
(0.289)\end{array}$ & $\begin{array}{c}2.982 \\
(0.282)\end{array}$ & $\begin{array}{c}3.734 \\
(0.277)\end{array}$ \\
\hline $\operatorname{Test}^{1)}: \chi^{2}(2)$ & $\begin{array}{l}\text { n.a. } \\
\text { n.a. }\end{array}$ & $\begin{array}{c}0.093 \\
(0.630)\end{array}$ & $\begin{array}{c}1.109 \\
(0.600)\end{array}$ & $\begin{array}{c}3.625 \\
(0.170)\end{array}$ \\
\hline
\end{tabular}

Slovak Republic - Total Outflows

\begin{tabular}{|c|c|c|c|c|}
\hline Year & $\mathbf{1 9 9 2}$ & $\mathbf{1 9 9 3}$ & $\mathbf{1 9 9 4}$ & $\mathbf{1 9 9 5}$ \\
\hline \multirow{2}{*}{ Elasticity } & $\begin{array}{c}\text { Estimate } \\
(\text { Std.Error })\end{array}$ & $\begin{array}{c}\text { Estimate } \\
(\text { Std.Error })\end{array}$ & $\begin{array}{c}\text { Estimate } \\
\text { (Std.Error })\end{array}$ & $\begin{array}{c}\text { Estimate } \\
(\text { Std.Error })\end{array}$ \\
\hline$\eta_{\mathbf{u}}$ & 0.082 & 0.092 & 1.698 & 1.383 \\
& $(0.320)$ & $(0.661)$ & $(0.654)$ & $(0.380)$ \\
$\eta_{\mathbf{s}}$ & -0.028 & 0.080 & 0.002 & -0.030 \\
& $(0.112)$ & $(0.127)$ & $(0.122)$ & $(0.116)$ \\
$\eta_{\mathbf{v}}$ & 0.135 & 0.236 & 0.078 & 0.064 \\
& $(0.092)$ & $(0.091)$ & $(0.092)$ & $(0.084)$ \\
$\mathbf{R T S}$ & 0.190 & 0.410 & 1.778 & 1.417 \\
& $(0.400)$ & $(0.756)$ & $(0.745)$ & $(0.488)$ \\
Test $^{\mathbf{1}} \mathbf{:} \chi^{\mathbf{2}} \mathbf{( 2 )}$ & n.a. & 0.066 & 1.661 & 0.164 \\
$(p-$ value $)$ & $n . a$. & $(0.970)$ & $(0.450)$ & $(0.930)$ \\
\hline
\end{tabular}

$\eta_{\mathrm{U}} \quad$ elasticity of the outflow with respect to the unemployment

$\eta_{\mathrm{s}}$ elasticity of the outflow with respect to the inflow into unemployment

$\eta_{\mathrm{v}} \quad$ elasticity of the outflow with respect to the vacancies

RTS returns to scale

Note: The elasticities and returns to scale are evaluated at the geometric means of the relevant variables.

1) Test of stability of RTS between neighboring years 
Figure 1:

Unemployment Rates in Central Europe

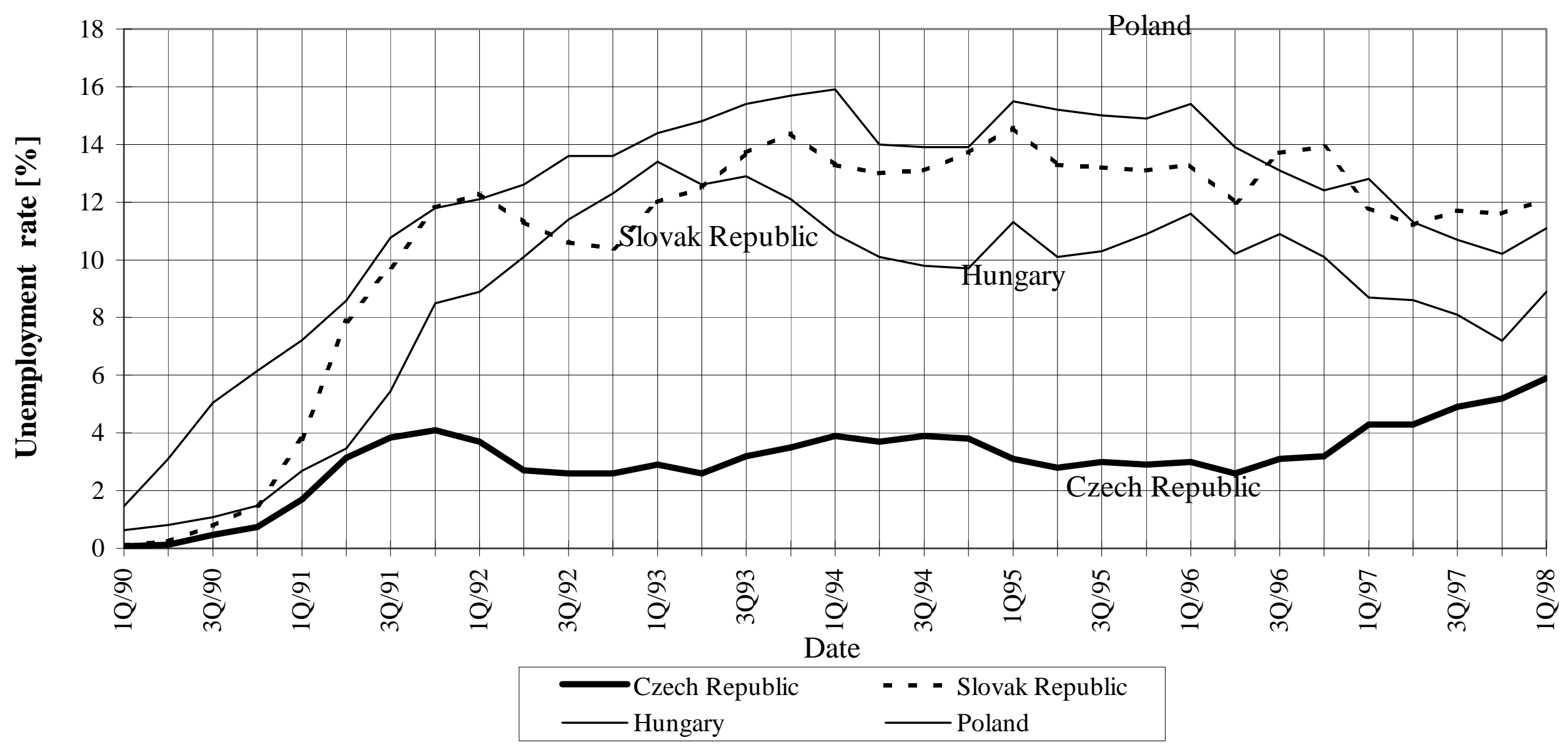

Source:1990-1991Unemployment in Transition Countries: Transient or Persistent?, OECD 1994, pg.29

1992-1996 Statistical Buletins Of the Czech Statistical Office, '93, '93, '95, '96/1, '97/2, '98/2. 


\section{Figure 2: \\ Unemployment and Vacancies in the Czech and Slovak Republic}

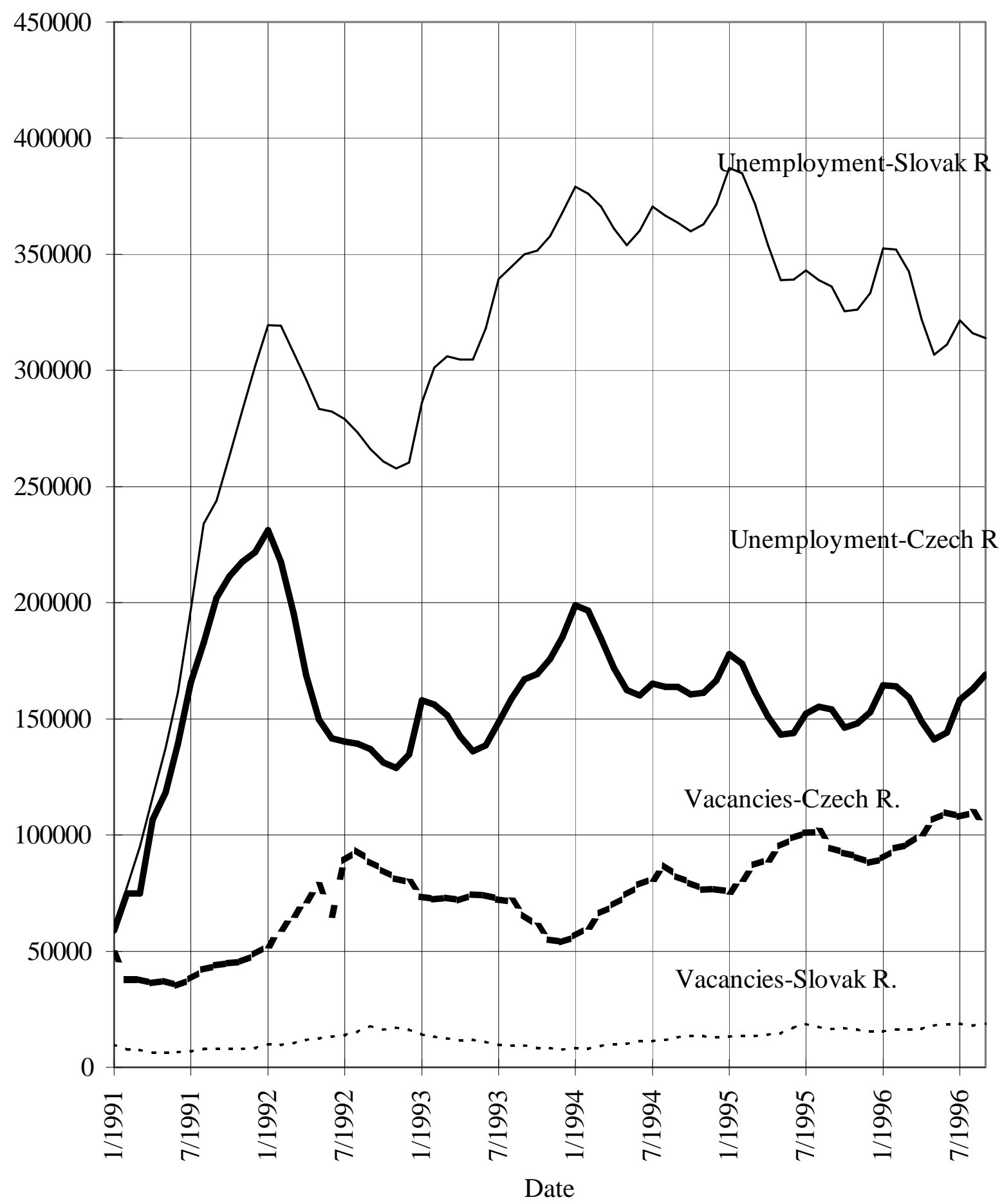

Unemployment-Czech Republic

- - Vacancies-Czech Republic

-Unemployment-Slovak Republic

. . . . - Vacancies-Slovak Republic 


\section{Figure 3 : \\ Beveridge Curve for the Czech and Slovak \\ Republic}

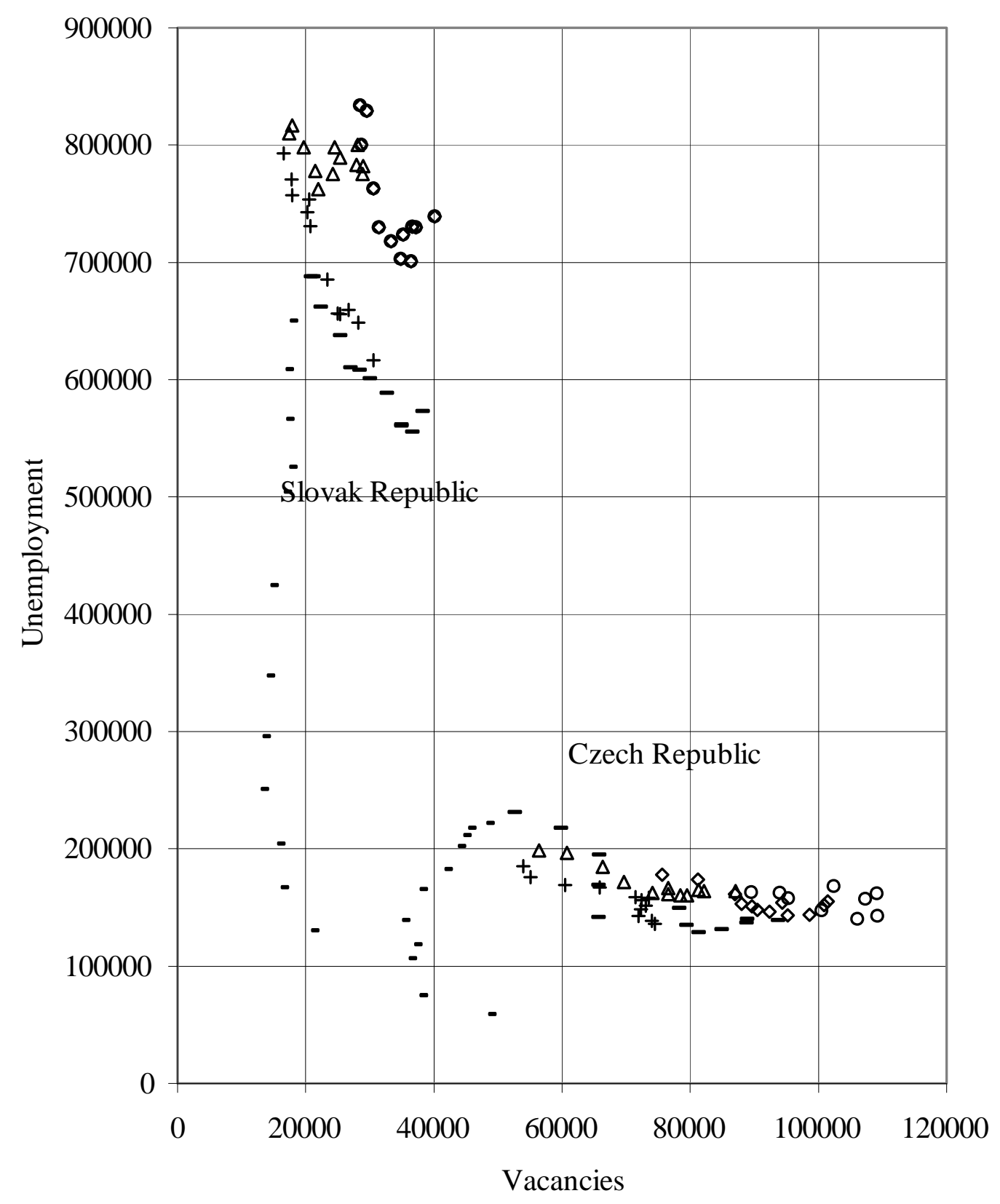

\begin{tabular}{|llll|}
\hline - U(CR)'91 & $-\mathrm{U}(\mathrm{CR})^{\prime} 92$ & $+\mathrm{U}(\mathrm{CR})^{\prime} 93$ & $\Delta \mathrm{U}(\mathrm{CR})^{\prime} 94$ \\
$\diamond \mathrm{U}(\mathrm{CR}){ }^{\prime} 95$ & $\circ \mathrm{U}(\mathrm{CR})^{\prime} 96$ & $-\mathrm{U}(\mathrm{SR}){ }^{\prime} 91$ & $-\mathrm{U}(\mathrm{SR})^{\prime} 92$ \\
$+\mathrm{U}(\mathrm{SR})^{\prime} 93$ & $\Delta \mathrm{U}(\mathrm{SR})^{\prime} 94$ & $\diamond \mathrm{U}(\mathrm{SR})^{\prime} 95$ & $\circ \mathrm{U}(\mathrm{SR})^{\prime} 96$ \\
\hline
\end{tabular}

Czech Republic (CR), Slovak Republic (SR) 
Figure 4:

Inflows into Unemployment in the Czech and

Slovak Republic

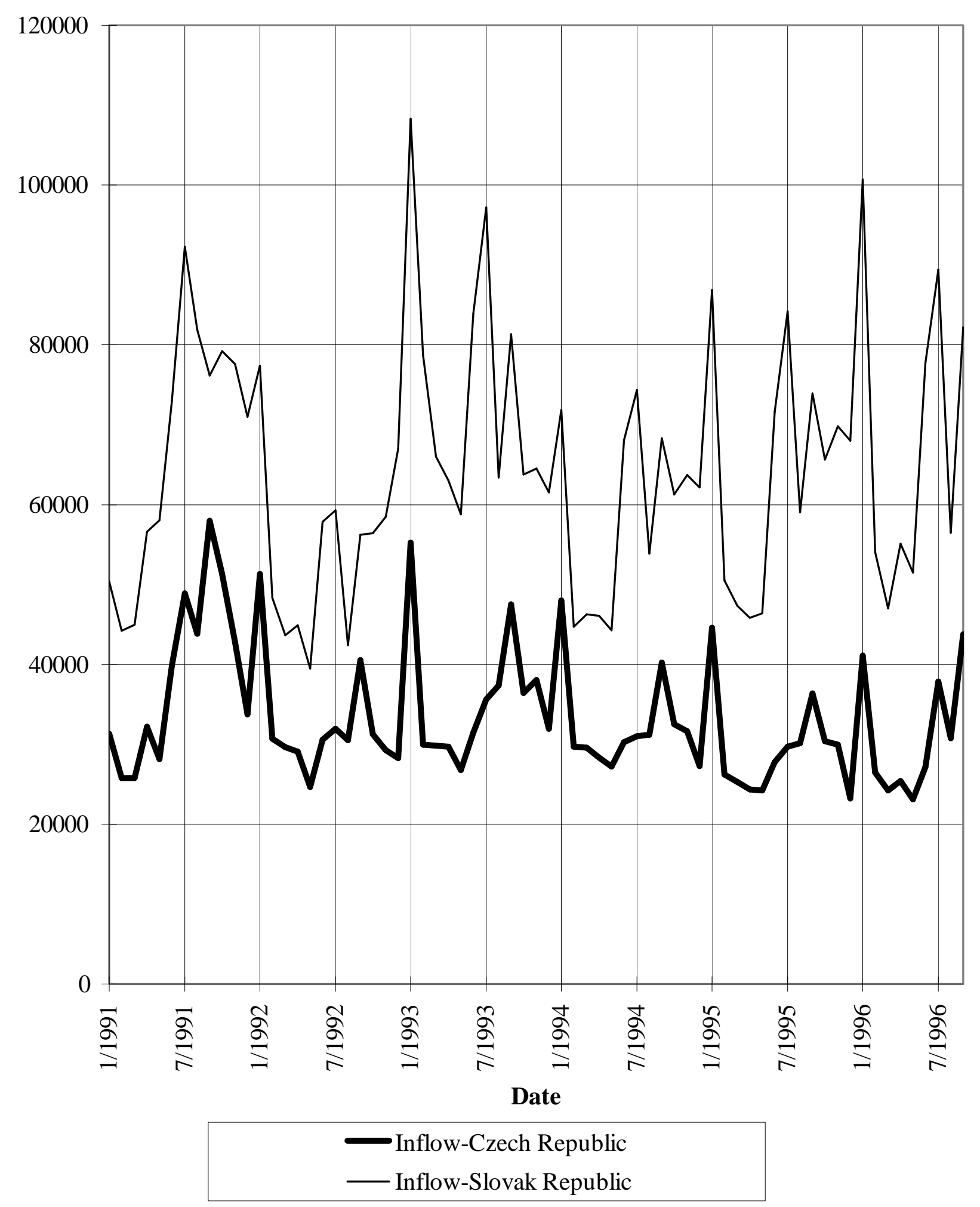




\section{Figure 5: \\ Outflows from Unemployment in the Czech and Slovak Republic}

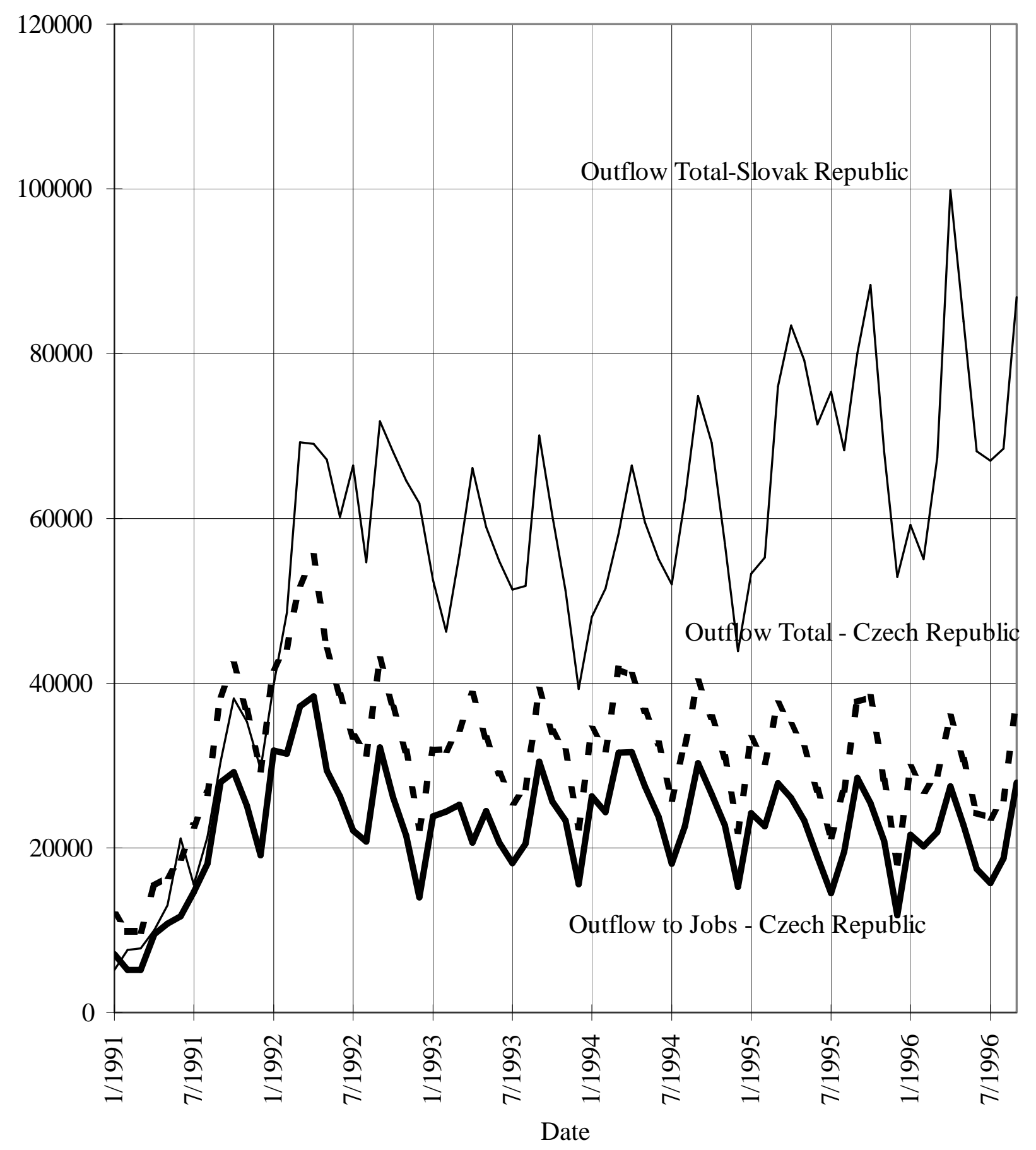

Outflow to Jobs-Czech Republic

- Outflow Total-Czech Republic

- Outflow Total-Slovak Republic 